\title{
PERCEÇÕES SOBRE AS ABORDAGENS À APRENDIZAGEM - ESTUDO DE VARIÁVEIS PSICOLÓGICAS
}

\author{
Abilio Afonso Lourenço* \\ Carla Maria Leite Nogueira **
}

\begin{abstract}
RESUMO
Esta investigação, realizada numa escola básica no norte de Portugal, tem como objetivo analisar as perceções que os alunos apresentam sobre algumas variáveis relativas à forma como desenvolvem a sua aprendizagem, nomeadamente: a autorregulação para a aprendizagem; os processos de estudo utilizados; o controlo volitivo; a planificação da gestão do tempo; e a procrastinação. Outra finalidade deste estudo éverificar se existe uma relação significativa entre estas variáveis e a perceção de autoeficácia revelada pelos alunos, assim como com os níveis exibidos no final do $1^{\circ}$ período, nas disciplinas de Língua Portuguesa, Inglês, Matemática e Ciências Naturais. São apresentadas, também, algumas implicaçõespara a prática educativa.
\end{abstract}

Palavras-chave: Abordagens à aprendizagem. Percepções de autoeficácia. Ensino básico.

\begin{abstract}
This research, conducted in a basic school in northern Portugal, aims to analyze the perceptions that students have about some variables regarding how to develop their learning, namely: self-regulation for learning; study the processes used, the control volitional; planning time management, and procrastination. Another purpose of this study is to determine whether there is a significant relationship between these variables and the
\end{abstract}

\footnotetext{
* Doutor em Psicologia da Educação pela Universidade do Minho, Braga, Portugal. Professor titular do Agrupamento de Escolas Alexandre Herculano, Porto, Portugal. Investigador da Universidade do Minho e do Centro de Investigação em Psicologia e Educação do Agrupamento de Escolas Alexandre Herculano.E-mail: privadoxy@gmail.com

** Licenciada em Matemática pela Faculdade de Ciências da Universidade do Porto. Professora de Matemática no Agrupamento de Escolas de S. João de Sobrado, Valongo, Portugal.E-mail: carlalnog@gmail.com
} 
perception of self-efficacy revealed by the students, as well as the levels shown at the end of the 1st period, in the discipline of Portuguese, English, Mathematics and Natural Sciences. We present also some implications for educational practice.

Keywords: Approaches to learning. Perceptions of self-efficacy. Basic education.

\section{Introdução}

Uma das preocupações atuais da comunidade educativa portuguesa prende-se, inequivocamente, com a problemática da aprendizagem dos alunos, bem como das estratégias utilizadas pelos mesmos para a obtenção do sucesso escolar. A magnitude do fenómeno e as óbvias implicações sociais sugerem que este não é apenas um assunto dos investigadores da área educacional, mas que nos confrontamos com uma inquietude e procura crescente de respostas e resultados por parte de toda a comunidade.

Os estudantes, quando entram na sala de aula, trazem ao contexto de aprendizagem uma conceção particular do propósito dessa mesma aprendizagem, um conjunto de convicções sobre eles próprios como estudantes fundeado numa história pessoal de (in)sucessos, bem como das crenças acerca do processo de aprendizagem e seus resultados (LOURENÇO, 2008). Posteriormente, são confrontados com o esforço a empreender nas metas propostas, no empenho das atividades, nos desafios a enfrentar em vários domínios, dentro e fora da escola (SCHUNK, 2005).

Atualmente, o foco da aprendizagem é dirigido para a importância dos pensamentos que o aluno vai traçando, bem como as dimensões cognitiva, comportamental e motivacional que este estimula nas aprendizagens que vai desenvolvendo. Conforme se refere Biggs (1991, p. 14), “os alunos aprendem por uma grande variedade de razões; essas razões determinam a forma como aprendem e esta determinará a qualidade do seu resultado".

Este novo paradigma da investigação perceciona os indivíduos como processadores da informação, realçando a forma como estes desenvolvem o processamento ativo do conhecimento, à medida que vão atribuindo significado e sentido ao ambiente que os rodeia, ou seja, implica a atribuição de um significado e de sentido ao que está a aprender (BIGGS, 1991). 
Hoje em dia, um dos caminhos apontados para o combate do insucesso escolar passa pela implementação de estratégias metacognitivas, motivacionais e comportamentais através das quais os alunos possam monitorizar a eficácia dos seus métodos de estudo e/ou estratégias de aprendizagem (ROSÁRIO; MOURÃO; SALGADO; RODRIGUES; SILVA; MARQUES; AMORIM; MACHADO; NÚÑEZ; PIENDAGONZÁLEZ; HERNANDÉZ-PINA, 2006). Por outras palavras, urge a necessidade de que os alunos sejam capazes de desenvolver conhecimentos, competências e atitudes que possam ser transferidas de um contexto de aprendizagem para outro e, desta forma, possam autorregular a aprendizagem. Assim, os saberes obtidos nos distintos contextos de aprendizagem podem, por sua vez, ser utilizados nos vários contextos de trabalho (PÉREZ; GONZÁLEZ-PIENDA; RODRIGUEZ, 1998).

Para uma melhor compreensão e operacionalização das dimensões em estudo, serão apresentados, seguidamente, alguns conceitos básicos sobre cada destas variáveis e o respetivo racional teórico em que se baseiam.

\section{Abordagem à aprendizagem, uma aproximação ao conceito}

Em 1976, na Universidade de Gotemburgo, Marton e Säljö (1976a, 1976b) descreveram, detalhadamente, dois modos de aproximação dos alunos à aprendizagem de um determinado texto: uma abordagem superficial, caracterizada pelo facto de as matérias serem aprendidas sem uma exigência compreensiva e integradora, com a vontade de atingir objetivos que são extrínsecos ao próprio material de aprendizagem; contrastando com uma abordagem profunda, a qual é caracterizada por um interesse intrínseco nas tarefas e na qual o aluno tenta compreender o material de aprendizagem relacionando-o com os seus conhecimentos prévios e com o mundo que o circunda (RICHARDSON, 1997). Os alunos, sugeriram aqueles investigadores, enfrentam uma determinada tarefa com uma determinada motivação que ativa, desejavelmente, uma estratégia de aprendizagem congruente. Esta relação metacognitiva entre uma motivação face a uma determinada tarefa que despoleta uma estratégia para a operacionalizar foi apelidada de abordagem à aprendizagem. Assim, a dicotomia superficial versus profunda denominou as formas habituais 
de os alunos abordarem as tarefas (MARTON; SÄLJÖ, 1976a, 1976b), as quais estão dependentes de o aluno, enquanto agente do seu processo de aprendizagem, tentar encontrar um significado na realização da tarefa, ou apenas reproduzir mecanicamente o seu conteúdo (ENTWISTLE, 1995).

Diversos investigadores (MARTON, 1988; MARTON, CARLSSON, HALÁSZ, 1992; MARTON, WATKINS, TANG, 1997; SÄLJÖ, 1982) sugeriram que as diferenças na qualidade das aprendizagens se relacionavam com abordagens à aprendizagem utilizadas. Este facto pode ser esclarecido considerando que os alunos utilizadores de uma abordagem mais superficial pareciam não compreender o significado das mensagens na totalidade, o que se encontrava ligado a níveis baixos de sucesso escolar; enquanto os alunos que optavam por uma abordagem profunda tentavam, particularmente, descobrir a mensagem do autor e compreender o significado associado à mesma, o que implicava uma visão profunda do aprender e resultados de aprendizagem mais robustos Rosário, Ferreira e Cunha (2003).

$\mathrm{O}$ conceito de abordagem à aprendizagem cunhado por Marton descreve o centro de atenção dos alunos ao defrontarem uma certa atividade de aprendizagem (ENTWISTLE, 1988). No respeitante à abordagem profunda, o aprendente efetua a tarefa de aprendizagem com a intenção de obter um significado pessoal do texto. Enceta um processo dinâmico de aprendizagem no qual desafia os pensamentos, os argumentos e as certezas expostas pelo autor, tentando descobrir pontos de ligação entre os pensamentos do texto e entre estes e a sua experiência pessoal. Este mecanismo exige que o aluno faça uma reorganização do conhecimento, construindo, por sua vez, uma estrutura própria. Na abordagem superficial não ocorre um envolvimento pessoal no ato de aprender, pois este é tido como uma obrigação extrínseca. $\mathrm{O}$ aluno foca a sua concentração apenas no texto propriamente dito, preocupando-se, particularmente, com a memorização de um maior número de acontecimentos e ideias apresentadas, sem se preocupar em estabelecer relações entre si. Alude, assim, a um mecanismo automático de memorização, no qual o aluno raramente diferenciará o fundamental do acessório (BIGGS, 2003).

As diversas investigações que fazem parte da literatura SAL (StudentApproaches to Learning), no que se refere às abordagens à 
aprendizagem (BARCA; PORTO; SANTORUM, 1997; PAIVA, 2008), relatam que a adoção de uma abordagem à aprendizagem superficial se encontra estatisticamente associada às classificações escolares inferiores. Deste modo, alguns investigadores, nomeadamente Marton (1988), enunciam operacionalmente a aprendizagem como a variabilidade no modo de compreender a realidade. O que diferencia a abordagem superficial da profunda tem a ver com a dimensão referencial. Por seu lado, o que discrimina as abordagens atomísticas e holísticas é a dimensão estrutural ou organizativa das abordagens à aprendizagem. A abordagem à aprendizagem exibe um aspeto estrutural holístico ou atomístico e o resultado da aprendizagem um aspeto hierárquico ou sequencial. A literatura (MARTON, 1988; MARTON; SÄLJÖ, 1997) tem frequentemente sugerido que os resultados hierárquicos tendem a combinar-se com as abordagens holísticas e os resultados sequenciais com as abordagens atomísticas. Contudo, na linha de investigação fenomenográfica, a abordagem e o resultado da aprendizagem não podem ser vistos como duas etapas do processo de aprendizagem afastadas temporalmente em níveis sucessivos: o processo e o seu fim (ROSÁRIO; GRÁCIO; NÚNEZ; GONZÁLEZ-PIENDA, 2007).

Marton concebe a aprendizagem defrontando, como duas dimensões indivisíveis, o aprendido (o resultado) e o como se aprende (o processo). A aprendizagem contém, como já foi mencionado, uma natureza relacional. Os modos como os sujeitos aprendem exprimem relações entre si e certas dimensões do mundo que os circunda. Assim, qualquer tentativa de aperfeiçoar a aprendizagem não se deve centrar nos sujeitos isolados mas sim nas relações como um todo (MARTON, 1988).

Concluindo, Marton e Booth (1997) investigaram as variáveis que influem nas experiências de aprendizagem dos alunos. Para os autores, é fundamental a história de vida dos indivíduos, no entanto, se os alunos consideram o estudo, e mais minuciosamente a leitura, como algo imposto, com muita dificuldade poderão revelar um bom rendimento no que diz respeito à execução das tarefas. Se, em contrapartida, os alunos olham para as tarefas como uma forma de descobrir e incrementar os seus conhecimentos sobre a realidade, mais facilmente conseguirão alcançar bons resultados de aprendizagem (MARTON; WEN; NAGLE, 1996). Neste sentido, 
Marton, Hounsell e Entwistle (1997) defendem que se quisermos produzir melhorias significativas na aprendizagem, não devemos tentar alterar duma forma avulsa o indivíduo ou o ambiente, mas antes a sua experiência e a sua conceção das atividades que tem que efetivar. Biggs (1988), por sua vez, interpreta o conceito de abordagem à aprendizagem como um processo que emerge da perceção dos alunos sobre as atividades a desempenhar, ancorado nas suas próprias características pessoais.

\section{Autorregulação da aprendizagem, um foco processual}

A abordagem à autorregulação da aprendizagem enfatiza a importância da atividade do sujeito no controlo do seu processo de aprendizagem numa perspetiva sociocognitiva, realçando os seus conceitos básicos. Considerando o marco teórico sociocognitivo e de acordo com Zimmerman e Martinez-Pons (1990), o construto da aprendizagem autorregulada está estritamente ligado aos pensamentos, sentimentos e ações criados pelos próprios alunos e, de uma forma sistemática, dirigidos para a execução dos seus objetivos programados. Para tal, os alunos devem recorrer ao uso constante de estratégias cognitivas, metacognitivas, motivadoras e comportamentais (Zimmerman, 2000). Alguns dos comportamentos que os alunos terão de acionar no processo autorregulatório da sua aprendizagem prendem-se com o estabelecimento de objetivos realistas e atempados, o desenvolvimento de um plano para orientar o seu estudo e utilizar diferentes estratégias de aprendizagem (PINTRICH, 2003). Sempre que o aluno averigue que não está a obter os resultados desejados deverá proceder a alterações nas suas estratégias de aprendizagem, monitorizando o seu estudo e procurando a ajuda de terceiros (ZIMMERMAN; RISEMBERG, 1997), ou sempre que seja possível frequentar programas de treino autorregulatório organizados pelas escolas (TIMOTHY; ZIMMERMAN, 2004).

A procura de ajuda é um dos fatores sociais que o aluno pode usufruir para autorregular a sua aprendizagem. Por sua vez, esta estratégia é influenciada por fatores pessoais e contextuais. Segundo Ryan e Pintrich (1997), os fatores pessoais abarcam as perceções dos alunos relativas à sua aptidão social e académica, atitudes e tipo de metas estabelecidas. 
Quanto aos fatores ambientais, onde se inclui o ambiente de sala de aula e a conduta do professor, Newman (1994) alega que numa situação de sala de aula mais aberta e participativa, bem como um comportamento mais sociável do professor, fomentam o pedido de ajuda por parte do aluno. Pintrich e Zusho (2002) referem que os alunos que têm a capacidade de autorregular a sua aprendizagem, quando confrontados com elementos distratores e obstáculos à aprendizagem na sala de aula, obtêm resultados e aprendizagens mais positivos do que os alunos que não apresentam essas capacidades autorregulatórias.

Algumas pesquisas deixam transparecer o paradoxo de que os alunos que mais carecem de ajuda na execução dos trabalhos escolares são os mesmos que a evitam (KARABENICK, 1998) e que a procura de ajuda está associada ao tipo de objetivos académicos que os alunos definem para si próprios (RYAN; PINTRICH, 1997). Assim, é imperioso que os fatores ambientais e sociais sejam entendidos por estes alunos como recursos em vez de barreiras à sua aprendizagem (YOWELL; SMYLIE, 1999), para que tal seja possível o papel dos professores é fundamental, mas os pais não se podem demitir desta tarefa.

Entretanto, Zimmerman (1989b) propôs uma formulação para explicar a aprendizagem autorregulada baseada na teoria triárquica sociocognitiva de Bandura (1986), onde era sugerido que os esforços dos estudantes para regular a sua aprendizagem envolviam três tipos de determinantes: (i) as características pessoais; (ii) o comportamento dos alunos; e (iii) o ambiente. Assim, os estudos sobre a autorregulação da aprendizagem evidenciam-se por adotarem uma perspetiva específica perante o processo de aprendizagem e os seus determinantes. Em vez de se focarem, apenas, nas características pessoais dos alunos e/ou do ambiente que os rodeia, realçam que a aprendizagem é um processo que o aluno pode iniciar, desenvolver e controlar. A tónica ultrapassa o determinismo das circunstâncias socioculturais, familiares ou pessoais, para se centrar no papel de agente ativo e diligente do sujeito que assume a iniciativa de controlar as suas ações em maior ou menor grau (SCHUNK, 2001).

A aprendizagem autorregulada descreve um sistema estruturado de múltiplas dimensões onde são abrangidas componentes pessoais (e.g., cognitivos e emocionais), comportamentais e contextuais e, também, como 
um processo aberto, que prevê atuações cíclicas, por parte do aluno, no desenrolar das fases do processamento de aprendizagem (SCHUNK, 2005). Na perspetiva de Pintrich (2000, p. 435) a aprendizagem autorregulada:

[...] é um processo ativo e construtivo através do qual os alunos estabelecem objetivos para a sua aprendizagem e tentam monitorizar, regular e controlar a sua cognição, motivação e comportamento, guiados $[\ldots]$ pelos seus objetivos e pelas características contextuais do seu ambiente. Estas atividades autorregulatórias podem mediar a relação entre os indivíduos, o contexto, e todas as suas realizações.

Segundo Lourenço (2008), um aluno autorregulado caracterizase, assim, por (i) estabelecer atempadamente objetivos concretizáveis; (ii) elaborar um plano de estudo; (iii) modificar, sempre que necessário, o tipo de estratégia durante a aprendizagem; (iv) monitorizar o seu estudo, procurando ajuda sempre que necessário (e.g., professores, família, pares); (v) mudar o ambiente de estudo sempre que este for desestabilizador; (vi) interromper o estudo quando se sente cansado; e (vii) estabelecer autorrecompensas quando efetivamente cumpriu o horário de estudo previamente estabelecido. Zimmerman e Risemberg (1997) confirmaram estas diferentes dimensões da aprendizagem (e.g., a motivação, os métodos, a gestão do tempo, o ambiente físico e social e a realização) como sendo competências autorregulatórias fundamentais para os estudantes atingirem a mestria e o sucesso escolar.

Tendo em consideração o marco teórico sociocognitivo, o construto da autorregulação da aprendizagem defendido por Zimmerman e MartinezPons (1992, p. 284) referem que:

Em termos dos processos cognitivos os alunos autorreguladores, planeiam, organizam, automonitorizam-se, e autoavaliam-se durante o processo de aprendizagem. Motivacionalmente os alunos autorregulados percebem-se como autoeficazes, autónomos e intrinsecamente motivados. Em termos comportamentais, os alunos autorreguladores selecionam, estruturam e até "criam" os ambientes sociais e psíquicos que otimizam a sua aprendizagem. 
Um aluno autorregulado é operacionalmente definido por Zimmerman (1994) como aquele que, para rentabilizar a sua aprendizagem, planifica, implementa e controla o seu método de estudo, utilizando estratégias específicas de aprendizagem mediadas pelas suas perceções de autoeficácia. Neste processo são tangíveis aspetos qualitativos e quantitativos, pois envolve tanto os processos que o aluno emprega como a frequência da sua utilização (ZIMMERMAN; MARTINEZ-PONS, 1990). Ainda segundo alguns autores, os alunos com estas características constituem-se como pró-ativos, elegem metas que vão além das determinadas nos currículos disciplinares, adequam as suas capacidades para monitorizar as atividades de estudo e são eficazes no seu planeamento estratégico (BOEKAERTS, 1996).

Entende-se, assim, que estes alunos possam controlar três dimensões da aprendizagem (MONTERO; TORRES, 1998): (i) a cognição - porque interiorizaram um conjunto de estratégias cognitivas e metacognitivas e conseguem aplicá-las num contexto de estudo, além de lhes possibilitar adquirir um conhecimento de si próprios e das exigências de cada tarefa; (ii) a motivação e os afetos - devido a poderem dominar e alterar as suas crenças motivacionais, nomeadamente as perceções de autoeficácia ou o estabelecimento de objetivos, adequando-as a cada situação; e (iii) os comportamentos observáveis - que permitem aos alunos criar e organizar os seus espaços de aprendizagem e de realização das tarefas, possibilitando, assim, controlar os meios ao seu alcance.

Para que o processo autorregulatório se desenvolva, efetivamente, em cada uma destas dimensões, torna-se necessário que o aluno tenha a possibilidade de escolher e controlar a sua aprendizagem. Para Zimmerman (1994) é importante que os alunos possam fazer opções eficazes para a sua aprendizagem, bem como controlem as dimensões basilares dessa mesma aprendizagem, para autorregularem o seu comportamento. Nesta sequência, as investigações indicam como principais características da autorregulação da aprendizagem: a escolha e o controlo (ROSÁRIO; NÚÑEZ; GONZÁLEZ-PIENDA, 2007). A perceção de escolha é aceite como uma das variáveis principais do processo autorregulatório, pois permite ao aluno perceber e selecionar a alternativa de ação que melhor se adapta ao seu padrão de aprendizagem. 
Do exposto e em consonância com a literatura da autorregulação da aprendizagem, podemos realçar três aspetos fundamentais para o estudo e entendimento dos processos autorregulatórios da aprendizagem: (i) as estratégias de autorregulação da aprendizagem - onde se inserem os métodos, tais como a organização e transformação do material a ser aprendido, a busca de informação, a repetição e o exercício da memória compreensiva (ZIMMERMAN; MARTINEZ-PONS, 1988); (ii) as perceções de autoeficácia - referem-se ao entendimento dos alunos acerca das suas aptidões para adequar e desenvolver as atividades necessárias com a finalidade de alcançar uma determinada meta escolar ou o incremento de uma capacidade para executar uma tarefa específica (BANDURA, 1986); e (iii) o estabelecimento de objetivos escolares - relaciona-se com o querer e poder estabelecer objetivos escolares por parte dos alunos, variando quanto à sua natureza e tempo necessário para os alcançar (ROSÁRIO, 1999), considerando a necessária motivação, por longos períodos de tempo, para atingir esses mesmos objetivos (ZIMMERMAN, 1989b). Por sua vez, Schunk (1994) adianta que um aluno é considerado autorregulador da sua aprendizagem quando na sua atitude perante o estudo controla as suas ações, cognições, intenções e afetos relativos às suas realizações comportamentais.

\section{$4 O$ controlo volitivo}

$\mathrm{Na}$ perspetiva sociocognitiva, a sequência cíclica natural da aprendizagem autorregulada está bem configurada no modelo das três fases da autorregulação sugerido por Zimmerman (1998, 1999, 2000). O processo decorre em três fases fundamentais: prévia, controlo volitivo, e autorreflexão, onde é descrito como dinâmico e aberto e subentendendo-se uma atuação cíclica por parte do aluno.

A fase prévia antecede a realização e reporta-se ao processo que designa o quadro da ação, ou seja, o processo onde o aluno coloca para si metas desafiantes e viáveis a curto prazo. Em simultâneo, o aluno ajuíza a sua capacidade (autoeficácia) para alcançar os objetivos que delineou. A fase de controlo volitivo respeita ao processo que se desenvolve no decurso dos atos que o aluno diligencia com vista a obter os objetivos que 
projetou (LOURENÇO, 2008), como por exemplo, a escolha conveniente de estratégias de aprendizagem (e.g., definir um horário de estudo, usar mnemónicas). Finalmente, a fase de autorreflexão acontece depois da realização. $\mathrm{O}$ aluno faz uma avaliação da eficácia das estratégias de aprendizagem empregues para conseguir os seus objetivos, executando os ajustamentos que julga serem pertinentes (NÚÑEZ; SOLANO; GONZÁLEZ-PIENDA; ROSÁRIO, 2006). Devido à natureza cíclica do processo, a fase de autorreflexão, por sua vez, influi na fase prévia seguinte, designadamente, na qualidade e quantidade do esforço a utilizar e no tipo de estratégias de aprendizagem a aplicar, perfazendo-se, desta forma, o ciclo autorregulatório (ROSÁRIO; SOARES; NÚÑEZ; GONZÁLEZPIENDA; RÚBIO, 2003; ZIMMERMAN, 2000).

$\mathrm{Na}$ fase de controlo volitivo, a variável em estudo, Zimmerman e Paulsen (1995) reconhecem dois processos importantes: o autocontrolo e a automonitorização. No primeiro processo estão incluídas as autoinstruções, as imagens mentais, focalização da atenção, as estratégias empregues na realização das tarefas e a ajuda aos alunos para se focalizarem nas atividades e rentabilizarem os seus esforços. $\mathrm{O}$ segundo processo é dirigido à atenção que o aluno consagra a facetas particulares da sua realização, às circunstâncias que lhe estão associadas e aos resultados produzidos (KUHL, 1985).

As autoinstruções abrangem as autoverbalizações que o indivíduo concretiza à medida que vai realizando atividades de aprendizagem (SCHUNK, 1998). Os estudos desenvolvidos neste tema indiciam que estas verbalizações ajudam no progresso da aprendizagem, exercendo uma função substancial no controlo da atenção, na introdução de estratégias passo-a-passo, no incitamento positivo e na conservação dos padrões motivacionais dos alunos (ROSÁRIO, 1999; SCHUNK, 1984; ZIMMERMAN; RISEMBERG, 1997). Estas especificidades das autoinstruções contribuem para que este seja um dos processos mais usados na monitorização do ensino de estratégias de aprendizagem a alunos com baixo rendimento escolar (BOEKAERTS, 2005; CORNO, 2004).

Relativamente às imagens mentais, outra técnica de autocontrolo, são utilizadas como apoio na codificação da informação e na realização escolar (e.g., visualizar mentalmente parte de um texto de um livro durante 
a realização de um teste). A focalização da atenção faculta, por seu lado, a focalização nas atividades, precaver-se de fatores distratores e outras contingências externas à tarefa. Investigações realizadas salientam que este conhecimento é fundamental para se obter uma aprendizagem eficaz (CORNO, 1993; KUHL, 1985). Os alunos que apresentam fracos resultados escolares desconcentram-se com mais facilidade e tendem a centrar-se mais nos erros praticados do que os alunos que expressam um elevado rendimento escolar (FIGUEIRA, 1994). O segundo processo da fase de controlo volitivo, a automonitorização, é avaliado como fundamental para os processos autorregulatórios, uma vez que dá a conhecer ao aluno os seus avanços e recuos face a um determinado critério de referência (e.g., resultados académicos, objetivos escolares definidos, êxito escolar dos pares) (LOPES DA SILVA; SÁ, 2003; WINNIE, 1995). No modelo concebido por Zimmerman (1998; 2000; 2002) são observáveis três configurações de automonitorização: (i) a monitorização associada com a autoavaliação; (ii) a monitorização associada com a implementação de estratégias; e (iii) a monitorização associada com os esforços para adequar as estratégias a partir dos resultados obtidos. Estas configurações são ciclicamente interdependentes - o estabelecimento de objetivos e o planeamento estratégico dependem das autoavaliações prévias e, por sua vez, influenciam a automonitorização posterior numa cadeia de ciclos adaptativos a contextos específicos. Monitorizar a fixação dos devidos ajustes durante os esforços cíclicos pode ajudar a conservar as perceções de eficácia dos alunos até alcançarem a mestria numa atividade ou tarefa estabelecida. Consequentemente, a automonitorização das atividades escolares vai sendo cada vez mais direcionada, devido à automatização das rotinas na solução de problemas e ao autoconhecimento que o aluno obtém acerca das suas capacidades e o seu comportamento (ZIMMERMAN; PAULSEN, 1995).

\section{Procrastinação}

Como professores, uma grande questão com que nos deparamos frequentemente na prática educativa é: por que razão alguns alunos tendem a dedicar-se às tarefas escolares com afinco enquanto outros as adiam até 
ao limite máximo possível ou não as concluem de todo? Obviamente que, depois desta questão, se seguiram outras... Será uma característica da pessoa? Ou será uma questão ligada ao contexto e ao tipo de tarefa a executar? Será que as raparigas e os rapazes apresentam perfis diferenciados em relação a esta característica? A procrastinação evoluirá com a idade? A procrastinação ocorrerá sempre ou apenas em momentos específicos? Os alunos autorregulados, que tendem a demonstrar maior interesse escolar e estão mais predispostos ao envolvimento na aprendizagem, serão também afetados pela procrastinação?

A procrastinação é frequentemente definida como um comportamento que implica o atraso no início ou término das tarefas (FERRARI; HARRIOT; EVANS; LECIK-MICHNA; WENGER, 1997) ou tomada de decisão (DEWITTE; LENS, 2000), quer o prazo para o término tenha sido estabelecido pela própria pessoa quer tenha sido estabelecido por terceiros/as (HARRIS; SUTTON, 1983). Nesta linha de ideias, a procrastinação académica foi definida como a realização de tarefas escolares (preparar trabalhos escritos ou exames) no último momento possível (ZIESAT; ROSENTHAL; WHITE, 1978) ou implicando a não conclusão de uma tarefa escolar dentro da moldura temporal definida para o efeito (SENÉCAL; KOESTNER; VALLERAND, 1995), sendo considerado como um problema bastante frequente (FERRARI; JOHNSON; MCCOWN, 1995).

Apesar de a procrastinação abranger todos os tipos de tarefas e de todos os tipos de procrastinação serem relevantes, a pertinência do estudo da procrastinação escolar ou académica é elevada uma vez que a vida dos estudantes se caracteriza pelo cumprimento de prazos (FERRARI; O'CALLAGHAN; NEWBEGIN, 2005). Considerando, ainda, que a procrastinação poderá simultaneamente ser antecedente e consequência de desajustamento psicológico (FERRARI; JOHNSON; MCCOWN, 1995) é surpreendente que, comparativamente a outros construtos psicológicos, a investigação sistemática tenha apenas sido iniciada há cerca de apenas vinte e cinco anos (SCHOUWENBURG, 2004).

Considerando, ainda, que o estudo da procrastinação em contexto escolar é pertinente uma vez que pode ter consequências negativas para pessoas em idade escolar (dado que são frequentemente confrontadas 
com prazos); que se verifica que no ensino básico não tem sido, a nível internacional, objeto de investigações no âmbito da procrastinação (SCHER; OSTERMAN, 2002); que o estudo e intervenção nas questões de género se devam fazer de forma mais precoce possível (GAINE; GEORGE, 1999), foi opção consagrar uma pequenaparte deste estudo a este público-alvo. A procrastinação, a ativação e a energia que a realização de tarefas no último momento possível propicia são experiências muito familiares no contexto educativo, pelo que encontrar formas adaptativas de as ultrapassar se tornou também num dos objetivos deste trabalho.

\section{A gestão do tempo de aprendizagem}

A motivação e as competências de organização dos tempos de estudo dos alunos em contexto escolar constituem-se como elementos imprescindíveis para a qualidade nos diversos níveis e modalidades de ensino, assumindo papéis especiais no Ensino Básico, principalmente pelos constantes desafios impostos à Escola (LOURENÇO; PAIVA, 2010a). Dentre estes desafios destacam-se o compromisso da inovação e da responsabilidade social, as quais configuram um desafio ainda maior: manter uma comunidade escolar permanentemente motivada, produtiva e, ainda, orientada pelo pressuposto da mestria educativa. Nesse contexto, em que estar motivado e gerir o tempo dedicado às atividades escolares representa o primeiro passo para qualquer prática de sucesso escolar, abordar, discutir, refletir sobre a motivação, suas variáveis e indicadores, consolida-se, também, como um tema emergente.

A produção de conhecimento relacionada com a motivação tem crescido consideravelmente a nível internacional, especialmente a dedicada ao estabelecimento de metas a curto e longo prazo, ao passo que no contexto educacional português essa tendência é, ainda, discreta. A revisão de literatura acerca desta temática, relacionada ao Ensino Básico, demonstra que duas grandes teorias protagonizam as discussões realizadas: a Teoria da Autodeterminação (Self-DeterminationTheory) e a Teoria das Metas de Realização (AchievementGoalsTheory). Também é possível detetar um aumento de produção relacionado a uma terceira: a Teoria da Perspetiva de Tempo Futuro (Future Time Perspective). Seguidamente, serão abordados sucintamente cada uma destas teorias. 


\subsection{Teoria da Autodeterminação}

A Teoria da Autodeterminação (TAD) foi proposta pelos norteamericanos Eduard Deci e Richard Ryan, já em meados da década de 1970 (DECI; RYAN, 1985). Tornou-se amplamente aceite e difundida em diversos campos do conhecimento, sobretudo no contexto educativo. $\mathrm{O}$ foco de análise reside na orientação dos motivos que orientam os comportamentos, estabelecendo para estes diferentes locus e causalidade: o interno e o externo. Desse binómio surgem as duas principais orientações motivacionais que fundamentam a teoria - a motivação intrínseca e a extrínseca.

A motivação intrínseca corresponde a um comportamento tipicamente autodeterminado, no qual o interesse por uma atividade está pautado pela livre escolha, pela espontaneidade e pela curiosidade. O empenho dedicado para a realização de uma atividade não está vinculado com as contingências externas e com recompensas, mas sim, com as características inerentes à própria atividade (DECI, 2000). Nesse contexto, em que as tarefas possuem fins em si mesmas, os teóricos relatam que o comportamento intrinsecamente motivado está mais associado com sentimentos de satisfação, realização e prazer (REEVE, DECI; RYAN, 2004).

Já na motivação extrínseca, a atividade ou tarefa está subordinada à obtenção de uma meta ou resultado. Segundo Deci e Ryan (2000), nessa situação a realização das ações está muito relacionada com recompensas, avaliações, prazos, punições, elogios, entre outros aspetos. O que determina o comportamento está muito mais associado ao controlo, agenciado por vontades externas, no qual o indivíduo age sob pressão, em detrimento da livre vontade e da autonomia. Nesse comportamento controlado, o sujeito tende a perceber as atividades/tarefas como instrumentais para obtenção de determinado objetivo. Entretanto, o que figura em primeiro plano é o objetivo final e não a própria tarefa/atividade.

Para Ryan e Deci (2000, p. 68) o comportamento autodeterminado é regido pelo atendimento de três características básicas, que os autores definem como "necessidades psicológicas inatas": as necessidades de "autonomia" (autonomy), "competência" (competence) e "pertença" (relatedness). A autonomia é entendida como o exercício da livre vontade, 
da eleição e condução dos comportamentos, sem muita regulação ou controlo externo. Com essa necessidade, o sujeito experimenta o próprio comportamento, sendo esse iniciado e continuado a partir das suas escolhas. Os autores apontam que os sujeitos são autónomos quando percebem um locus de causalidade interno, um alto nível de liberdade, um baixo nível de controlo externo e a possibilidade de escolha na realização das ações (RYAN; DECI, 2000).

Já a competência reside em nutrir perceções de eficácia pessoal através de experiências que conduzam a determinados objetivos. As pessoas são propensas a se envolverem em atividades que se adaptam às suas habilidades e a níveis atuais de conhecimento, mantendo dessa forma, a necessidade de se perceber eficaz nas interações sociais. Segundo Reeve, Deci e Ryan (2004) isso reflete no desejo natural de exercitar as próprias capacidades e desenvolver novas competências.

Por fim, a perceção de pertença e apoio a um determinado grupo refere-se ao relacionamento e à necessidade de estabelecer relações interpessoais significativas em contextos específicos (RYAN; DECI, 2000). Juntamente com a perceção de autonomia e competência, aperceção de pertença constitui-se como elemento determinante do comportamento intrinsecamente motivado.

Segundo Ryan e Decy (2000, p. 68), essas três características "parecem ser essenciais para facilitar as disposições naturais para o crescimento e integração, bem como para um desenvolvimento social construtivo e bem-estar pessoal". Também afirmam que "o desenvolvimento saudável requer a satisfação de todas as três necessidades", de forma que o atendimento de "uma ou duas não são suficientes" (RYAN; DECI, 2000, p. 229). De acordo com os investigadores, não há um bom desenvolvimento se alguma dessas necessidades for negligenciada. As mesmas constituem-se como necessidades interdependentes e integradas, de forma que "a satisfação de cada uma delas reforça e fortalece as demais”(RYAN; DECI, 2000, p. 244).

\subsection{Teoria das Metas de Realização}

Recentemente, a chamada Teoria das Metas de Realização (TMR) tem sido apontada como uma das mais importantes contribuições da Psi- 
cologia Contemporânea voltada aos contextos educativos. A partir de uma grande difusão na década de 80 do século XX, ela procura analisar como a adoção de determinadas metas ocasiona diferentes modelos motivacionais nos alunos (ANDERMAN; MAEHR, 1994). Nessa perspetiva, as metas constroem-se por um conjunto de pensamentos, crenças, propósitos e emoções que expressam as expectativas dos alunos, representando diferentes modos de enfrentar as tarefas académicas (AMES, 1990).

De acordo com os teóricos, a TMR diferencia, fundamentalmente, dois tipos de metas: a meta de aprendizagem e a meta de desempenho (ELLIOTT; DEWECK, 1988). A meta de aprendizagem está caraterizada pelo desejo de buscar novos conhecimentos, destrezas e competências. Ao incorporar estes elementos o aluno direciona mais energia para o enfrentamento das atividades, valorizando a própria atividade e o processo a ela inerente, além de utilizar estratégias metacognitivas e atribuir o sucesso ao próprio esforço. Já a meta de desempenho, também conhecida como meta relacionada ao ego, está pautada pelo desejo de sentir-se bem frente aos outros ou pelo desejo de não sentir-se incapaz. Neste caso o que prevalece é a obtenção de uma meta/objetivo, contexto em que a realização das tarefas assume uma importância secundária. O sentido da realização de uma atividade/tarefa está condicionado à obtenção de uma meta/objetivo final, estando esse tipo de comportamento muito associado à instalação de ambientes competitivos (LOURENÇO; PAIVA, 2010b). Bzuneck (1999) ressalta que, embora exista um contraste entre os dois tipos de metas, os alunos não costumam orientar-se exclusivamente por uma ou outra, podendo, frequentemente, ocorrer orientações simultâneas nas metas de aprendizagem e desempenho, uma vez que essas estão imbricadas. No entanto, salienta-se que a orientação dominada pela meta de aprendizagem produz resultados mais positivos sobre a aprendizagem (BORUCHOVITCH, 2008).

\subsection{Teoria da Perspetiva de Tempo Futuro}

O surgimento da Perspetiva de Tempo Futuro (PTF) está muito relacionado aos estudos do psicólogo belga Joseph Nuttin (1909-1988). Para Nuttin (1985, p. 135), a motivação é "uma tendência específica em direção a um determinado objeto e sua a intensidade está em função da natureza e 
da relação que o sujeito mantém com esse objeto". O comportamento surge do dinamismo de uma "necessidade", através da qual o sujeito identifica "objetos desejados", desenvolvendo a partir desses, "projetos de ação". O objetivo e o projeto de ação relacionam-se com a noção de perspetiva futura. Para o autor, o futuro psicológico está essencialmente relacionado com a motivação.

Nuttin e Lens (1985) especificam que a perspetiva futura representa um processo que tem como fim um objetivo a ser alcançado a médio ou longo prazo. Apesar do estabelecimento de metas futuras, essas construções estão intimamente relacionadas com o momento presente do indivíduo. Afirmam o quão importante é possuir uma perspetiva futura e, ao manter um valor positivo em relação a essa projeção, o sujeito tende a realizar as tarefas presentes com maior envolvimento, atribuindo valor mais elevado em relação aos comportamentos que possam estar relacionados com o objetivo alvo.

Lens (1993, p.70) caracteriza a PTF como a "integração do futuro cronológico no momento presente do indivíduo". Segundo ele, as perspetivas futuras podem ser fixadas em maior ou menor espaço de tempo. Para o autor, não se trata de um tempo cronológico, mas subjetivo, pois diferentes espaços de tempo podem ocasionar distintos impactos motivacionais.

Nesse sentido, o autor especifica três níveis de Perspetiva Futura: $P F$ extensa, $P F$ restrita e $P F$ alongada. Diz que jovens que estabelecem objetivos-alvo a serem atingidos num futuro distante, são dotados de uma PF extensa. Os que perseguem objetivos que se devem realizar num futuro próximo, são caracterizados por uma $\mathrm{PF}$ restrita. Aqueles que se orientam por uma PF mais distante, podendo esperar por muitos anos para obterem seus objetivos, em geral, são capazes de adiar consideravelmente suas satisfações imediatas e, ainda assim, permanecerem orientados para a obtenção da meta.

Ampliando o entendimento acerca das perspetivas futuras, De Volder e Lens (1982) salientam dois aspetos relacionados ao desenvolvimento da PTF: o cognitivo e o dinâmico. O aspeto cognitivo relaciona-se à antecipação do futuro distante. Permite ao sujeito dispor de maior intervalo de tempo para situar metas motivacionais, planos, projetos e orientar ações no presente em direção aos objetivos futuros. Assim, as 
ações adquirem um maior valor de "utilidade" sendo desenvolvida uma maior perceção de "instrumentalidade" em relação às atividades presentes. $\mathrm{O}$ aspeto dinâmico está ligado à atribuição de grande valor aos objetivos alvo, mesmo que estes possam ser alcançados somente num futuro distante. Enquanto o aspeto cognitivo está relacionado com a antecipação do futuro, com o planeamento e com o grau de utilidade das tarefas presentes, $\mathrm{o}$ aspeto dinâmico refere-se à intensidade com que se valorizam as metas futuras.

No sentido de associar as principais teorias motivacionais contemporâneas, Vansteenkiste, Simons, Lens, Sheldon e Deci (2004) realizaram um estudo correlacional focalizando duas orientações motivacionais: a meta futura intrínseca (future intrinsic goal) e a meta futura extrínseca (future extrinsic goal). Os resultados apontam que os sujeitos adotam metas futuras intrínsecas ao possuírem maior autonomia, desenvolvem senso de instrumentalidade às ações presentes, apresentam resultados mais favoráveis e persistem mais nos comportamentos orientados ao futuro (LOURENÇO; ROSÁRIO; SALGADO; GUIMARÃES; TRIGO; BALDAQUE; COSTA; PAIVA; SANTOS; MOURÃO; MAGALHÃES; VALLE; NÚÑEZ; GONZÁLEZ-PIENDA, 2008).

Feito um enquadramento teórico às variáveis em estudo, no capítulo seguinte são apresentados os resultados alcançados, a partir das respostas obtidas nos questionários aplicados aos alunos, a interpretação estatística dos mesmos e algumas implicações educativas.

\section{Método}

\subsection{Objetivos}

Como já foi explicitado anteriormente, a presente investigação teve como objetivo avaliar as influências de algumas variáveis relativamente à forma como os alunos desenvolvem a sua aprendizagem, nomeadamente: a autorregulação da aprendizagem; os processos de estudo utilizados; o controlo volitivo; a planificação da gestão do tempo; e a procrastinação. Outro objetivo deste estudo foi tentar verificar se existe uma relação significativa entre estas variáveis e a perceção de autoeficácia exibida pelos alunos, assim como com os níveis exibidos no final do $1^{\circ}$ período nas disciplinas de Língua Portuguesa, Inglês, Matemática e Ciências Naturais. 


\subsection{Amostra}

Participaram no estudo 235 alunos distribuídos por onze turmas, sendo 94 (40\%) do $7^{\circ}$ ano de escolaridade, 71 (30.2\%) do $8^{\circ}$ e $70(29.8 \%)$ do $9^{\circ}$ ano. Na amostra considerada, $119(50,6 \%)$ alunos são do sexo masculino e $116(49,4 \%)$ do feminino, com idades compreendidas entre os 12 e os 15 anos $(M=13,31 ; d p=.944)$. Não foi incluída nesta amostra uma turma de CEF (Curso de Educação e Formação), devido à sua especificidade e ao reduzido número de alunos, evitando, assim, enviesamento dos dados e consequentes interpretações.

\subsection{Instrumentos}

Os instrumentos usados na investigação que possibilitaram medir as variáveis em estudo são: i) a Ficha de Dados Pessoais e Escolares (FDPE); ii) o Questionário de Autoeficácia num Domínio, cujo objetivo é saber as perceções de autoeficácia dos alunos num determinado domínio (e.g., Língua Portuguesa, Matemática, etc,); iii) o Inventário de Processos de Autorregulação da Aprendizagem (IPAA) (ROSÁRIO; LOURENÇO; PAIVA; NÚÑEZ; GONZÁLEZ-PIENDA; VALLE, 2011), que pretende medir até que ponto os alunos estabelecem metas para a sua aprendizagem e tentam monitorizar, regular e controlar a sua cognição, motivação e comportamento, guiados pelos seus objetivos e pelas características contextuais do seu ambiente; iv) o Inventário de Processos de Estudo (IPE) (ROSÁRIO; FERREIRA; CUNHA, 2003), que tem como objetivo principal avaliar as formas comuns de os alunos abordarem as tarefas e as perceções que possuem acerca dos seus ambientes de aprendizagem, tendo em consideração as suas características pessoais e as situações de ensinoaprendizagem em que estão inseridos; v) o Questionário de Estratégias de Controlo Volitivo (QECV) (LEITE, 2008), que visa aferir os processos que se desenvolvem no decurso dos atos que o aluno diligencia com vista a obter os objetivos que projetou, ou seja, num primeiro processo estão incluídas as autoinstruções, as imagens mentais, focalização da atenção, as estratégias empregues na realização das tarefas e a ajuda aos alunos 
para se focalizarem nas atividades e rentabilizarem os seus esforços e, num segundo processo, é dirigido à atenção que o aluno consagra a facetas particulares da sua realização, às circunstâncias que lhe estão associadas e aos resultados produzidos; vi) o Inventário da Planificação da Gestão do Tempo (IPGT) (LOURENÇO; PAIVA, in press), que tem como objetivo avaliar em que medida as metas se constroem por um conjunto de pensamentos, crenças, propósitos e emoções que expressam as expectativas dos alunos, representando diferentes modos de enfrentar as tarefas académicase; vii) o Questionário de Procrastinação (QP) (ROSÁRIO; COSTA, 2007) que permite avaliar a capacidade dos alunos relativamente à realização de tarefas escolares (preparar trabalhos escritos ou exames) no último momento possível ou originando a não conclusão de uma tarefa escolar dentro da moldura temporal definida para o efeito, implicando o atraso no início ou término das tarefas ou tomada de decisões.

Para avaliar a variável tempo de estudo dos alunos, foi utilizada uma pergunta aberta na FDPE onde estes eram questionados sobre o número de horas que dedicavam ao estudo numa semana. Relativamente ao aproveitamento escolar, foi avaliado tendo como base os níveis obtidos no final do $1^{\circ}$ período nas disciplinas de Língua Portuguesa, Inglês, Matemática e Ciências Naturais, através de informação recolhida, igualmente, na FDPE.

Foram escolhidas disciplinas curriculares representativas do domínio das letras e das ciências, bem como se teve em consideração as disciplinas sujeitas a exame nacional.

Para avaliar a autoeficácia num domínio foi usada uma escala qualitativa de cinco pontos, desde Muito Bom (1) a Mau (5) e nos restantes instrumentos foi utilizada uma escala Likert de cinco pontos, desde Nunca (1) a Sempre (5).

\subsection{Procedimentos}

Foram aplicados os questionários aos alunos em fevereiro de 2012, após a autorização da Direção da escola, tendo sido assegurada a confidencialidade das respostas. O tratamento estatístico dos dados foi 
realizado com base no programa informático SPSS/AMOS 20.0 tendo como suporte os pressupostos teóricos referidos por Byrne (2001) e Lowe, Winzar e Ward (2007).

\section{Resultados}

Os resultados que seguidamente se apresentam correspondem à totalidade da amostra $(\mathrm{N}=235)$. Do Quadro 1 é possível observar que, nos três anos de escolaridade, os alunos apresentam uma média de idades ajustada ao nível de estudos que frequentam, sendo de realçar que os rapazes exibem sempre valores superiores relativamente às raparigas.

No que diz respeito às horas de estudo, é visível que à medida que se avança no ano de escolaridade vai aumentando o número de horas despendidas pelos alunos numa semana de sete dias. Geralmente, é o sexo feminino que se aplica mais ao estudo, embora no $8^{\circ}$ ano de escolaridade o sexo oposto mostre médias ligeiramente superiores. Na amostra, são os rapazes do $7^{\circ}$ ano que dedicam menos tempo ao estudo $(\mathrm{M}=4.25$; $\mathrm{dp}=4.771$ ), em contraste com as raparigas do $9^{\circ}$ ano de escolaridade que exibem uma média bastante superior $(\mathrm{M}=11.43$; $\mathrm{dp}=6.651)$. É possível observar, ainda, que $16 \%$ dos alunos do $7^{\circ}$ ano de escolaridade não dedicam qualquer tempo ao estudo durante a semana e, cerca de $50 \%$, estuda menos de 4 horas nesse período. No $8^{\circ}$ ano, $1,4 \%$ dos inquiridos refere não estudar durante a semana e 53,5\% destinam menos de 5 horas. Quanto ao $9^{\circ}$ ano de escolaridade, embora se denote um incremento relativamente aos restantes anos de escolaridade, $1,4 \%$ dos estudantes menciona ser nulo o tempo dedicado ao estudo durante a semana e 50\% utilizam menos de 7 horas nesse mesmo espaço temporal. De realçar que neste ciclo de estudos as raparigas dedicam bastante mais tempo ao estudo do que os seus colegas.

O facto do desvio padrão (dp) encontrado nas horas de estudo dos rapazes do $7^{\circ}(\mathrm{dp}=4.771)$ e $8^{\circ}$ anos $(\mathrm{dp}=7.545)$ ser superior às médias, respetivamente $(\mathrm{M}=4.25)$ e $(\mathrm{M}=6.86)$, poderá ser justificado devido aos valores manifestados por alguns alunos ser muito superior à média estimada para os respetivo ano de escolaridade e género, o que enviesa os dados encontrados. 
Quanto aos níveis de avaliação às disciplinas em estudo, em Portugal, os níveis de avaliação são estimados entre 1 e 5, correspondendo os valores 1 e 2 a níveis negativos e os restantes a níveis positivos. Assim, a Língua Portuguesa e a Matemática apresentam valores negativos nos três níveis de escolaridade e em ambos os sexos, com exceção das raparigas do $9^{\circ}$ ano de escolaridade na disciplina de Matemática $(\mathrm{M}=3.00 ; \mathrm{dp}=.716)$. Em ambas as disciplinas são as raparigas que apresentam sempre os melhores resultados nos três anos de escolaridade, contudo são os rapazes do $8^{\circ}$ ano que exibem as piores médias. Relativamente às disciplinas de Inglês e Ciências Naturais os níveis apresentados pelos alunos, de ambos os sexos, são substancialmente superiores, verificando-se, apenas, uma média negativa nos rapazes do $7^{\circ}$ ano de escolaridade, à disciplina de Inglês, e nos alunos do $8^{\circ}$ ano, na disciplina de Ciências Naturais, em ambos os sexos.

Fazendo uma análise comparativa entre os níveis atingidos pelos alunos no $1^{\circ}$ período e as suas perceções sobre a autoeficácia em cada uma das disciplinas, é possível inferir algumas discrepâncias nas avaliações feitas pelos alunos. Assim, na disciplina de Língua Portuguesa ambos os sexos, em todos os anos de escolaridade, apresentaram uma tendência em sobrevalorizar ligeiramente a perceção da autoeficácia relativamente aos níveis atingidos, sendo mais evidente nos rapazes do $8^{\circ}$ ano de escolaridade. Na disciplina de Inglês existe uma maior coerência entre os níveis obtidos e as perceções de autoeficácia, constatando-se uma ligeira sobrevalorização nos rapazes do $7^{\circ}$ ano, onde se verifica uma média inferior a três, assim como uma subvalorização nas raparigas do $9^{\circ}$ ano de escolaridade, embora neste caso o nível médio atingido seja positivo.

No que concerne à disciplina de Matemática os alunos, de uma maneira geral, indicam níveis de perceção de autoeficácia superiores aos observados na realidade, com exceção das raparigas do $9^{\circ}$ ano de escolaridade que apresentam perceções ajustadas aos níveis efetivamente atingidos no final do período. De realçar que os alunos do $7^{\circ}$ e $8^{\circ}$ anos, em ambos os sexos, têm uma perceção negativa, embora próxima do nível três, sobre as suas capacidades cognitivas a esta disciplina, o que é coincidente com os níveis efetivamente atingidos. Os rapazes do $9^{\circ}$ ano de escolaridade são os que apresentam um maior desfasamento nas suas opiniões relativamente às perceções de autoeficácia na Matemática. 
Quanto à disciplina de Ciências Naturais, verifica-se que são os alunos do $8^{\circ}$ ano de escolaridade que mais sobrevalorizaram as perceções de autoeficácia, comparativamente com os resultados obtidos, pois são os únicos que obtêm níveis inferiores a três no final do período, embora muito próximos do "Suficiente". Uma vez mais, são os alunos do sexo masculino, do $9^{\circ}$ ano de escolaridade, que mais se afastam da realidade quanto às perceções de autoeficácia neste domínio, porquanto fazem uma avaliação de nível quatro $(\mathrm{M}=3.67 ; \mathrm{dp}=.661)$ quando, em rigor, a sua média se situa mais próxima do nível três $(\mathrm{M}=3.07$; $\mathrm{dp}=.740)$. Através do Quadro 1, e fazendo uma análise comparativa de médias, é possível observar que, de uma forma geral, é o sexo feminino que apresenta valores de perceção de autoeficácia mais próximos da realidade, tendo em consideração os níveis conseguidos nas disciplinas em estudo. 


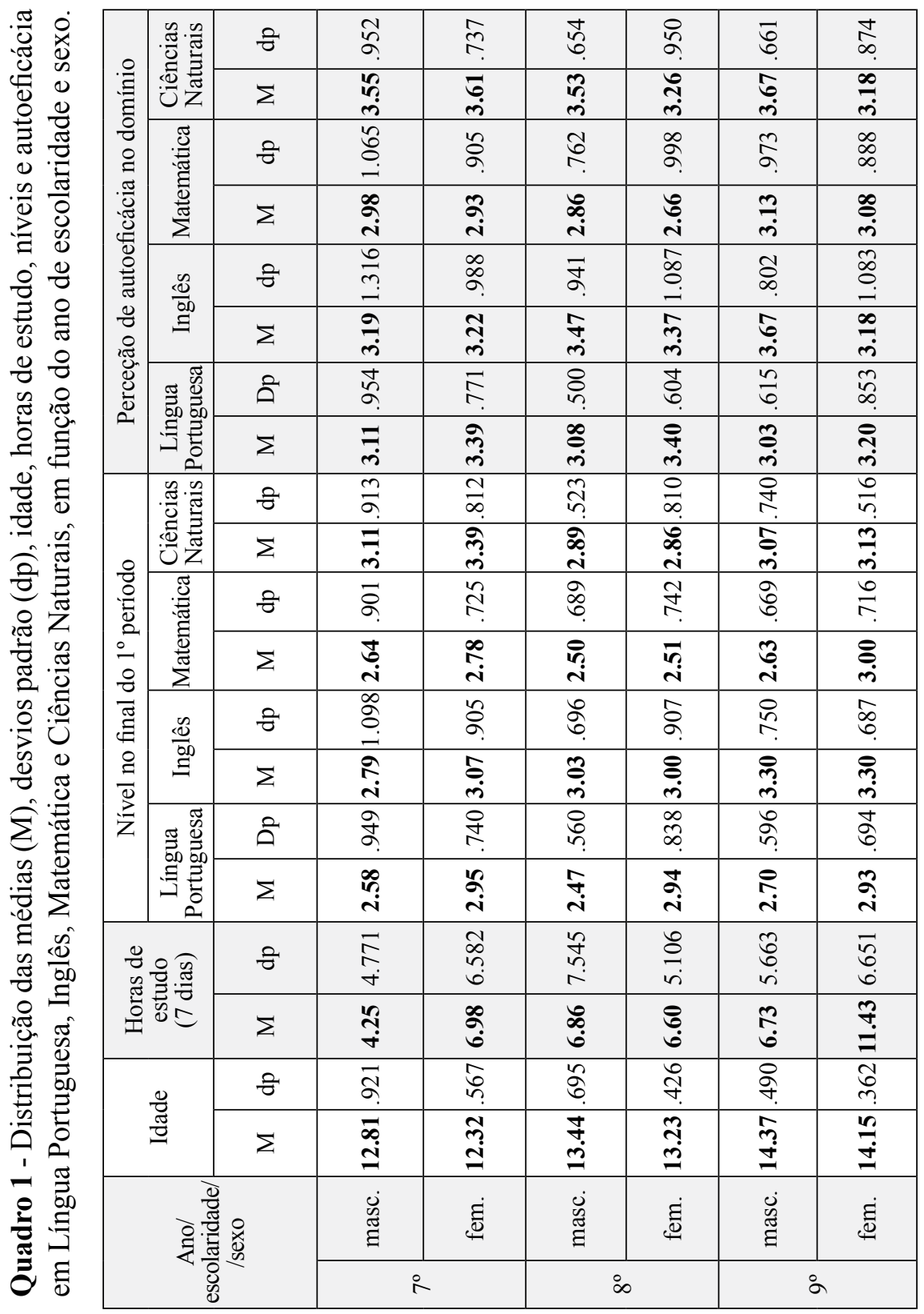


Relativamente às associações encontradas entre as variáveis em estudo, do quadro 2, é possível inferir que, nesta amostra de alunos do $3^{\circ} \mathrm{CEB}$, as raparigas são mais autorreguladas nos seus processos de aprendizagem $(\mathrm{M}=35,55 ; \mathrm{dp}=5,137)$ quando comparadas com os rapazes. Utilizam, também, melhores processos de estudo $(\mathrm{M}=38,97$; $\mathrm{dp}=5,476)$, possuem maior controlo volitivo nas atividades escolares $(M=39,20 ; d p=5,993)$, fazem uma melhor gestão do tempo escolar $(M=45,27 ; \mathrm{dp}=7,867)$ e adiam menos a realização das suas tarefas escolares $(M=21,83 ; d p=6,403)$. É no controlo volitivo (4.85), na autorregulação para a aprendizagem (4.69) e na gestão do tempo (4.69), onde se verifica uma maior diferença nas médias entre os géneros.

Quadro 2 - Associação entre a autorregulação da aprendizagem (IPAA), os processos de estudo (IPE), o controlo volitivo(QECV), a gestão do tempo (IPGT), a procrastinação (QP) e o sexo.

\begin{tabular}{ccccccc}
\hline \multicolumn{7}{c}{ SEXO } \\
\hline $\begin{array}{c}\text { Masculino } \\
\mathrm{N}=119\end{array}$ & $\begin{array}{c}\text { Feminino } \\
\mathrm{N}=116\end{array}$ & $\mathrm{~B}$ & $\mathrm{~T}$ & $\mathrm{P}$ & $\mathrm{R}^{2}$ \\
\hline IPAA & $30.86(7.599)$ & $35.55(5.137)$ & .341 & 5.534 & .000 & .116 \\
\hline IPE & $37.07(7.591)$ & $38.97(5.476)$ & .143 & 2.204 & .029 & .020 \\
\hline QECV & $34.35(9.132)$ & $39.20(5.993)$ & .300 & 4.796 & .000 & .090 \\
\hline IPGT & $40.58(10.358)$ & $45.27(7.867)$ & .248 & 3.899 & .000 & .061 \\
\hline QP & $25.73(7.220)$ & $21.83(6.403)$ & -.276 & -4.381 & .000 & .076 \\
\hline
\end{tabular}

De realçar que todos os valores encontrados são estatisticamente significativos, apresentando para a autorregulação da aprendizagem (IPAA) um valor de $p=.000$ e uma variância explicada de aproximadamente $12 \%$ $\left(\mathrm{R}^{2}=.116\right)$ relativamente às variáveis em estudo. Nas restantes variáveis observam-se, ainda, valores de $p=.029$ e uma variância explicada de $2 \%$ $\left(\mathrm{R}^{2}=.020\right)$ para os processos de estudo (IPE), $p=.000$ com uma variância explicada de $9 \%\left(\mathrm{R}^{2}=.090\right)$ para o controlo volitivo, um valor de $p=.000 \mathrm{e}$ uma variância explicada aproximada de $6 \%\left(\mathrm{R}^{2}=.061\right)$ para a gestão do tempo escolar e valores para a procrastinação para o estudo na ordem dos $7,6 \%$ $\left(\mathrm{R}^{2}=.076\right)$ para a variância explicada e um valor de significância de $p=.000$. 
De forma idêntica à utilizada com a variável independente (exógena) anterior, vejamos quais as associações verificadas entre as variáveis dependentes (endógenas) com a variável ano de escolaridade (cf. Quadro 3). Assim, comprova-se que são os alunos do $8^{\circ}$ ano de escolaridade que apresentam as melhores médias na autorregulação da aprendizagem $(M=34,34 ; d p=5,419)$, nos processos de estudo $(M=39,55 ; d p=5,976)$, na gestão do tempo dos assuntos escolares $(M=46,30 ; \mathrm{dp}=8,285)$, bem como são os que menos procrastinam, isto é, os que menos adiam a realização dos trabalhos respeitantes à escola $(\mathrm{M}=22,70 ; \mathrm{d} p=6,582)$. Apenas no controlo volitivo $(\mathrm{M}=38,90 ; \mathrm{dp}=6,631)$ o $9^{\circ}$ ano de escolaridade supera os restantes anos. Este resultado, por se encontrar no último ano deste ciclo de estudos, poderá ser justificado pelo facto nesta variável se reconhecerem dois processos importantes - o autocontrolo e a automonitorização -, componentes importantes que ajudam no progresso da aprendizagem, exercendo uma função substancial no controlo da atenção, na introdução de estratégias passo-a-passo, no incitamento positivo e na conservação dos padrões motivacionais dos alunos. Do quadro 3, é possível inferir, igualmente, que é o $7^{\circ}$ ano de escolaridade que apresenta os piores resultados em todas as variáveis em estudo. Das variáveis apresentadas, as únicas que estão relacionadas com o ano de escolaridade e anunciam valores estatisticamente significativas são: a autorregulação para a aprendizagem $(p=.010)$, com uma variância explicada de aproximadamente $3 \%\left(\mathrm{R}^{2}=.029\right)$, e o controlo volitivo $(p=.000)$, exibindo uma variância explicada de cerca de $6 \%\left(\mathrm{R}^{2}=.059\right)$. 
Quadro 3 - Associação entre a autorregulação da aprendizagem (IPAA), os processos de estudo (IPE), o controlo volitivo (QECV), a gestão do tempo (IPGT), a procrastinação (QP) e o ano de escolaridade.

\begin{tabular}{|c|c|c|c|c|c|c|c|}
\hline \multicolumn{8}{|c|}{ ANO DE ESCOLARIDADE } \\
\hline & $\begin{array}{l}7^{\circ} \text { ano } \\
N=94\end{array}$ & $\begin{array}{l}8^{\circ} \text { ano } \\
\mathrm{N}=71\end{array}$ & $\begin{array}{l}9^{\circ} \text { ano } \\
\mathrm{N}=70\end{array}$ & $\beta$ & $\mathrm{t}$ & $p$ & $\mathrm{R}^{2}$ \\
\hline IPAA & $\begin{array}{c}31.54 \\
(8.329)\end{array}$ & $\begin{array}{c}34.34 \\
(5.419)\end{array}$ & $34.19(5.670)$ & .169 & 2.615 & .010 & .029 \\
\hline IPE & $\begin{array}{c}37.10 \\
(7.954)\end{array}$ & $\begin{array}{c}39.55 \\
(5.976)\end{array}$ & $37.67(5.141)$ & --- & --- & --- & --- \\
\hline QECV & $\begin{array}{c}34.54 \\
(9.633) \\
\end{array}$ & $\begin{array}{c}37.54 \\
(6.394) \\
\end{array}$ & $38.90(6.631)$ & .244 & 3.836 & .000 & .059 \\
\hline IPGT & $\begin{array}{c}40.8 \\
(10.596)\end{array}$ & $\begin{array}{c}46.30 \\
(8.285)\end{array}$ & $\begin{array}{r}42.23 \\
(8.133)\end{array}$ & --- & --- & --- & --- \\
\hline QP & $\begin{array}{c}24.79 \\
(7.742)\end{array}$ & $\begin{array}{c}22.70 \\
(6.582)\end{array}$ & $\begin{array}{r}23.60 \\
(6.566)\end{array}$ & --- & --- & --- & --- \\
\hline
\end{tabular}

No que diz respeito aos dados obtidos entre a variável exógena "horas de estudo" e as restantes variáveis endógenas investigadas, constatase a existência de correlações relativamente fortes (cf. Quadro 4). Desta forma, verifica-se que as horas de estudo despendidas pelos alunos numa semana apresentam uma relação média com todas as outras variáveis, sendo de destacar o valor mais expressivo inferido para a autorregulação da aprendizagem $(\mathrm{r}=.445, p<.001)$. Quando se faz uma comparação entre as variáveis endógenas em estudo (IPAA, IPE, QECV, IPGT e QP), comprova-se que as relações são fortes, especialmente as observadas entre a autorregulação para a aprendizagem com a gestão do tempo $(\mathrm{r}=.791$, $p<.001$ ), com os processos de estudo ( $\mathrm{r}=.702, p<.001)$ e com o controlo volitivo $(\mathrm{r}=.701, p<.001)$. Existe, ainda, uma relação forte entre o controlo volitivo dos alunos e a gestão do tempo dos mesmos para desenvolver as atividades escolares $(\mathrm{r}=.708, p<.001)$. É de realçar, também, uma relação forte entre os alunos que apresentam um comportamento autorregulado e a procrastinação $(\mathrm{r}=-.697 ; p<.001)$, o que significa que, como era de se esperar, os alunos que se apresentam como mais autorregulados são os que menos adiam a realização das suas atividades escolares, cumprindo-as de uma forma mais assídua e regular. Assim, de uma forma geral, poder- 
se-á dizer que o aluno que se perceciona como autorregulado utiliza mais e melhores estratégias de estudo, diligencia comportamentos no sentido de alcançar os objetivos que projetou, como por exemplo, a escolha conveniente de estratégias de aprendizagem (e.g., define um horário de estudo, usa mnemónicas), mantém-se motivado para gerir o tempo que dedica às atividades escolares, como também não adia os seus trabalhos académicos, realizando-os e concluindo-os dentro da moldura temporal previamente definida para o efeito.

Quadro 4 - Correlação entre a autorregulação da aprendizagem (IPAA), os processos de estudo (IPE), o controlo volitivo (QECV), a gestão do tempo (IPGT) a procrastinação (QP) e as horas de estudo.

\begin{tabular}{lllllll}
\hline & HE & IPAA & IPE & QECV & IPGT & QP \\
\hline HORAS DE ESTUDO & --- & & & & & \\
IPAA & $.445^{* *}$ & --- & & & & \\
IPE & $.336^{* *}$ & $.702^{* *}$ & --- & & & \\
QECV & $.356^{* *}$ & $.701^{* *}$ & $.525^{* *}$ & --- & & \\
IPGT & $.369^{* *}$ & $.791^{* *}$ & $.652^{* *}$ & $.708^{* *}$ & -- & \\
QP & $-.338^{* *}$ & $-.697^{* *}$ & $-.425^{* *}$ & $-.628^{* *}$ & $-.675^{* *}$ & -- \\
\hline${ }^{*} p<.01 ;{ }^{* *} p<.001$ & & & & & & \\
\hline
\end{tabular}

Fazendo uma análise aos itens dos questionários que serviram de base para esta investigação, e tendo em consideração os valores máximos e mínimos em cada item, é possível observar que as pontuações obtidas em cada questão corroboram os resultados apresentados. Assim, tendo em conta os processos autorregulatórios dos alunos da amostra, estes dão grande importância ao local de estudo, procurando um sítio calmo e onde estejam concentrados, afastando-se de elementos distratores (da TV, das revistas de quadradinhos, dos jogos de computador, etc), comparam os resultados dos testes com os objetivos delineados para cada disciplina, como também guardam e analisam as correções dos trabalhos/testes, para ver onde erraram e saber o que têm de mudar para melhorar. Contudo, de uma maneira geral, não cumprem o horário de estudo que planeiam, embora analisem porque é que isso aconteceu e tiram conclusões para depois avaliar o rendimento do estudo, assim como não estão seguros 
de que são capazes de compreender o que lhes vão ensinando e por isso consideram a possibilidade de ter notas baixas.

Quanto aos processos de estudo, as respostas dos alunos vão no sentido de que quando recebem testes/trabalhos corrigidos, leem com cuidado as correções feitas e tentam compreender os porquês dos erros que fizeram, pedem aos professores que digam exatamente a matéria que sai no teste, porque só estudam isso, e investem tempo e esforço a tentar relacionar a matéria nova que estão a estudar com o que já sabem sobre esse tema. Por outro lado, apenas trabalham nas vésperas dos testes, estudando o que consideram suficiente para ter positiva, lendo só uma vez ou duas os apontamentos.

Relativamente aos resultados alcançados nas estratégias de controlo volitivo, os alunos foram colocados perante a seguinte situação:

Já deu o toque de entrada para a primeira aula da tarde. Tu e alguns dos teus colegas de turma continuam a divertir-se bastante no recreio da escola. Não te está a apetecer nada ir para a sala e está quase a terminar o "tempo de tolerância". Sabes que, nessa aula, o professor vai iniciar um novo tema e que seria importante acompanhares a matéria desde o início. Quando finalmente decides ir para a sala os teus colegas dizem que já estás muito atrasado e que não vale a pena ir, pois já vais ter falta...

Os resultados das pontuações dos itens indiciam que os alunos, de uma forma geral, se dirigem a correr para a sala de aula e pedem desculpa ao professor pelo atraso, pensam que se não conseguirem tirar boa nota nessa matéria, a responsabilidade será deles próprios, como também ir para as aulas é a melhor solução. Porém, as questões que obtiveram menor score são: "Afastar-me dos colegas e começar a andar para a sala" e "Pensar que, mesmo faltando à aula, não me vou divertir, porque não vou estar a fazer o que devia", o que demonstra uma certa contraposição nas suas atitudes e emoções.

Quando nos reportamos à planificação da gestão do tempo, nas atividades relativas à escola, as questões mais pontuadas prendem-se com objetivos a longo prazo, indicando que o que fazem hoje nas suas vidas é importante para o futuro, têm consciência dos níveis que querem obter no próximo período escolar, bem como têm uma perceção do que querem 
alcançar na escola depois do $9 .^{\circ}$ ano. Por sua vez, não se preocupam em fazer uma lista diária das coisas que têm de fazer, como também não estabelecem um conjunto de objetivos para cada dia.

No que concerne à procrastinação, isto é, o adiar ou eleger um comportamento que implique o atraso no início ou término das tarefas, os resultados obtidos são muito conclusivos. Os alunos indicam que não estão a par das matérias das diferentes disciplinas porque não estudam todos os dias, interrompem, frequentemente, o tempo de estudo para os testes para fazer outras tarefas (ouvir música, falar ao telemóvel...) e quando um trabalho é muito difícil desistem e passam para outra tarefa. Pode inferir-se dos resultados, ainda, que quando os alunos têm que realizar um trabalho importante para a escola, raramente optam por começar a fazê-lo atempadamente, ou seja, o mais cedo possível. Idêntica situação é observável quando o professor manda fazer uma tarefa na aula, levando algum tempo para iniciar o processo para a sua realização.

Concluída esta parte relativa à apresentação dos dados, torna-se necessário esclarecer que este trabalho de investigação tem um carácter essencialmente exploratório, sem qualquer pretensão de generalização, contudo, é vasto em resultados que poderão indiciar sugestões para investigações que arrisquem novos territórios do processo de ensino/ aprendizagem. Não obstante o tamanho da amostra, os resultados encontrados não se apresentam inadequados para descrever as relações entre as variáveis em estudo, mas sim incompletos para descrever a complexidade do processo de aprendizagem dos alunos do Ensino Básico. Os mesmos vão de encontro aos dados obtidos noutras investigações, quer nacionais quer internacionais, como também está de acordo com o racional teórico que serve de suporte às variáveis em estudo. Qualquer tentativa de investigação que pretenda descrever a multidimensionalidade dos processos de aprendizagem reflete, unicamente, uma imagem parcial do objeto de estudo (MAIA; GRAÇA, 1995).

Seguidamente serão apresentadas algumas conclusões do estudo e as presumidas implicações educativas que as mesmas poderão suscitar no seio da escola. 


\section{Conclusões e implicações educativas}

Aproximando-se o fim deste pequeno estudo, importa, agora, procurar sistematizar os seus contributos mais relevantes, refletindo sobre eles, na busca de um sentido integrador e coerente, e elencar um conjunto de pistas que conduzam a novos esforços de reflexão. Assumindo-o como um momento prévio, reflexivo, e espera-se que heurístico, pretende-se que seja, também, desencadeador de outras cogitações e de investigações que possam, inclusivamente, beneficiar da pertinência dos comentários, das fundamentações, das conclusões e mesmo das sugestões que aqui são deixadas, relativamente à importância das variáveis aqui estudadas e que se revelam importantes nos processos de aprendizagem dos nossos alunos.

Ao longo da apresentação do racional teórico, que deu suporte às variáveis em estudo, foram apresentadas algumas questões que serviram de norte para a prossecução deste trabalho. Assim, e tentando responder o mais sinteticamente possível, constata-se que apesar do construto da autorregulação da aprendizagem num determinado domínio ser relativamente recente, todas as investigações que se possam efetuar no seu âmbito poderão revestir-se de um grande impacto para a melhoria do ensino/aprendizagem das nossas escolas. Este enriquecimento pode ser observado na contribuição efetiva para a melhoria do rendimento escolar da maior parte dos nossos alunos, se os professores possuírem os conhecimentos subjacentes à temática da autorregulação da aprendizagem e se a exercitarem na prática. Para além deste conhecimento, será também importante que os professores e educadores possam avaliar o tipo de comportamento autorregulado que os alunos exibem para poderem intervir adequada e atempadamente nas disfunções que possam surgir. É também essencial que conheçam o impacto de algumas variáveis significativas (e.g., número de reprovações, tempo deestudo, perceções de autoeficácia percebida) no comportamento autorregulado manifestado pelos alunos e possuam competências que lhes permitam ensinar e modelar a utilização de estratégias autorregulatórias na sala de aula, tendo sempre como objetivo principal a mestria dos alunos.

Para o incremento destas competências é fundamental que os professores reflitam sobre o processo de ensino/aprendizagem encarando 
a aprendizagem como uma experiência pessoal em que o aluno deve participar ativa, autónoma, informada e dedicadamente (PAIVA; LOURENÇO, 2011c). Para tal, torna-se necessário a construção de ambientes de aprendizagem promotores da autorregulação, onde tanto os alunos como os professores compreendam a complementaridade dos seus papéis e implementem modelos realistas de autorregulação na aprendizagem. Neste sentido, a função principal dos professores será o de ajudar os alunos a assumirem as suas responsabilidades no seu próprio processo de aprendizagem (ZIMMERMAN; BONNER; KOVACH, 1996).

Quanto à perceção de si próprio como aluno, particularmente a competência percebida, a literatura sugere, recorrentemente, que a autoeficácia académica dos alunos é uma variável preditora do nível de investimento na aprendizagem (SCHUNK, 1996a; LOURENÇO, DA ROSA; PAIVA, 2010), contudo não é única nem se constitui como um fator que atue demodo isolado (SCHUNK, 1991; LOURENÇO, 2004). As crenças nas capacidades para alcançar as metas estabelecidas influem na motivação e no esforço do aluno para aprender, na qualidade do processamento da informação, provavelmente mais profundo, e no seu rendimento escolar. Perante determinadas tarefas, no caso em que as competências já estejam bem estabelecidas ou os comportamentos já assegurados pelo facto de serem rotineiros, não se torna imprescindível que o aluno pondere a sua autoeficácia. Esse julgamento mais facilmente será necessário quando se alterarem ou as condições pessoais ou as condições da tarefa, como novos conteúdos, nova disciplina ou aspetos semelhantes (SCHUNK, 1991). Igualmente, não se devem descartar as influências das expectativas de resultados, que são as crenças quanto aos efeitos prováveis das ações. Os alunos não se motivarão a agir caso prevejam resultados negativos das suas ações, muito embora se percebam capazes de as realizar, e, mesmo que antevejam resultados positivos, estes devem, ainda, ser valorizados para que o aluno os procure com as suas ações. Assim, na escola, os alunos devem valorizar (instrumentalizar) a qualidade das tarefas, a alta performance e até as classificações elevadas. Caso esses efeitos finais não tenham nenhum significado ou valor para eles, de nada adianta para a motivação eles acreditarem nas suas capacidades.

Assim, na realização das tarefas previstas no currículo, os 
professores poderiam discutir com os alunos a aplicação das estratégias de autorregulação a situações concretas, treinando a sua transferência para outros contextos e tarefas escolares (BOEKAERTS; CORNO, 2005). Os alunos seriam, deste modo, ajudados a responderem mais eficazmente aos seus objetivos e estilos de aprendizagem (ZIMMERMAN, 1989b). A literatura refere que os alunos a quem os professores, de uma forma sistemática, ensinam e modelam estratégias de autorregulação de aprendizagem aplicadas a diferentes tarefas escolares, mais facilmente exercitarão autonomamente a sua utilização (ABLARD; LIPSCHULTZ, 1998; ZIMMERMAN; SCHUNK, 1998).

Estes resultados constituem um desafio aos professores e educadores sugerindo-lhes, por um lado, a urgência da discussão das crenças dos alunos face à aprendizagem. Estas antecedem os comportamentos de estudo, determinando-os, e sugerem também uma reflexão apurada sobre o tipo de estimulação autorregulatória que poderá ser promovida quer na sala de aula, quer no estudo pessoal em casa (BIGGS, 1993).

É, também, importante conhecer as conceções dos alunos acerca da sua situação de aprendizagem e atuar de modo a desenvolver contextos de ensino e aprendizagem que os alunos vivenciem como motores de abordagens à aprendizagem profundas. Isto implica necessariamente a opção por uma abordagem centrada no aluno (PROSSER; TRIGWELL, 2000). Como refere Shuell (1986, p. 429),

a tarefa fundamental dos professores é conseguir que os alunos se envolvam nas atividades de aprendizagem, alcançando os resultados pretendidos [...] Convém recordar que aquilo que os alunos realizam é mais importante para a determinação do aprendido do que aquilo que o professor faz.

Ao analisar as distintas maneiras de os alunos abordarem a aprendizagem, Marton (1975) teve como princípio o facto de que os alunos adotam diferentes abordagens mesmo quando sujeitos às mesmas condições de aprendizagem, dependendo das suas conceções de aprendizagem e das suas conceções sobre si mesmos como aprendentes. Rosário, Ferreira e Guimarães (2001) destacam que a opção por uma certa abordagem à aprendizagem corresponde a uma combinação metacognitiva entre uma 
determinada motivação que orienta o aprender dos alunos e a estratégia adequada que a operacionaliza, representando uma resposta dos alunos à exigência percecionada do contexto em função dos seus objetivos específicos.

A prática docente poderá estimular os alunos a desenvolverem abordagens à aprendizagem mais significativas, encaminhando a atenção dos mesmos mais para o entendimento das matérias do que para a sua reprodução nas fichas de avaliação sumativa. No entanto, tal desiderato educativo requer o recurso a metodologias ativas que fomentem diferentes abordagens às tarefas escolares, e a métodos de avaliação que enfatizem a estrutura dos conteúdos em vez da memorização de assuntos independentes, entre outros aspetos. Ainda que a literatura refira a dificuldade em estimular os alunos a adotarem uma abordagem profunda à aprendizagem, propõe a necessidade demodificar o contexto de ensino/aprendizagem com a finalidade de alterar as perceções dos alunos acerca deste. Este passo é importante se pretendemos desenvolver o sucesso educativo.

$\mathrm{Na}$ medida em que a abordagem transmissiva parece desencorajar a adoção de uma abordagem profunda por parte dos alunos, pensamos ser útil que os professores se esforcem no sentido de refletirem sobre o modo como abordam o seu ensino. Devem ter como meta identificar, reduzir ou mesmo remover os fatores do seu ensino que parecem estimular a adoção de uma abordagem superficial à aprendizagem por parte dos alunos (e.g., prazos, tipos e modos de avaliação, liberdade na escolha de tópicos dos trabalhos) (BIGGS; MOORE, 1993).

A perceção das contingências contextuais, nomeadamente, como é percebido o ambiente de aprendizagem, o tipo de competição, a tolerância ao erro, o grau de agressividade percebida e a qualidade da interajuda entre os pares, contribuirão para avaliar em que medida a perceção de ambientes de aprendizagem mais ou menos fogosos e estimulantes, pode contribuir para a adoção de uma determinada abordagem, mais ou menos implicada compreensivamente. É indispensável, então, uma boa gestão das dificuldades que possam despontar para que a harmonia esteja presente no ambiente escolar e não interfira no processo de ensino e aprendizagem (LOURENÇO; PAIVA, 2009). Como referem Rosário, Núñez, González-Pienda, Almeida, Soares e Rúbio (2005), num dos seus estudos, a conceção de aprendizagem apresenta um efeito direto e significativo sobre a motivação profunda. Esta relação sugere, uma vez que 
os valores superiores na conceção de aprendizagem significam conceções de aprendizagem profundas, que a crença na aprendizagem como um caminho para a construção de um entendimento mais substantivo da realidade, tentando estabelecer relações entre factos, se encontra associada a um interesse intrínseco no material de estudo no qual os alunos vivenciam um envolvimento pessoal no ato de aprender.

A seleção e a organização dos conteúdos curriculares podem ser consumadas de modo a influenciar as abordagens à aprendizagem. Nesta sequência, é proposto o princípio basilar de que o âmago principal do ensino sejam os objetivos e não as matérias (RAMSDEN, 1992). Um segundo princípio evidente de seleção dos conteúdos é o de que para incutir uma motivação intrínseca devem ser usados assuntos tidos como relevantes e interessantes pelos alunos - o que provavelmente exige alguma liberdade de escolha dos alunos sobre eles (MONTGOMERY, 1994).

Assim, perceções de um ensino de qualidade e de liberdade na escolha do método e dos conteúdos de estudo fomentam nos alunos abordagens mais profundas e comportamentos mais positivos face ao estudo (FEARN-WANNAN, 1980). Neste contexto, um clima educativo afetuoso e cognitivamente estimulante é detentor de pré-requisitos para $\mathrm{o}$ incremento e promoção de uma abordagem à aprendizagem profunda. A abordagem superficial aparece, nomeadamente, como resposta a perceções de excesso de trabalho, de pouco tempo para completar as tarefas académicas e ainda de impedimento de selecionar os conteúdos de aprendizagem (NICHOLLS, 1984). Por este motivo é importante construir contextos educativos em que se fomentem o desejo e a autoconfiança dos alunos na sua capacidade de pensar sobre si próprios e quebrar a lógica implícita de ensino centrado nos conteúdos e no cumprimento do programa e as mensagens de que uns pensam esabem, cabendo a outros o papel de reter e reproduzir os conhecimentos (PAIVA; LOURENÇO, 2011a,b).

A promoção de ambientes que os alunos entendam como capazes de induzir uma abordagem profunda e em que possam realizar aprendizagens significativas, constitui o desafio sugerido ao sistema educativo em geral e aos professores em particular. A investigação científica destaca a influência da perceção dos alunos sobre os métodos de ensino e de avaliação usados pelos docentes e das matérias que integram o currículo na adoção de uma determinada abordagem à aprendizagem. 
Quanto à procrastinação, os dados vêm confirmar que se trata de um comportamento relativamente comum em contextos escolares, pelo que a pertinência do estudo desta variável é elevada uma vez que a vida dos estudantes se caracteriza pelo cumprimento de prazos. Em termos educacionais, é ainda visível que, ao contrário do que se passa noutros países, não tem existido qualquer preocupação com a adoção de programas de prevenção e intervenção na procrastinação no estudo. Urge, assim, que Portugal defina linhas orientadoras para estas temáticas, criando uma verdadeira política educativa nacional integrada, que se preocupe mais com os processos subjacentes à aprendizagem do que com os resultados propriamente ditos. Só assim será possível atingir a proficiência educativa.

Paralelamente, é ainda importante atender à perceção que os professores e educadores em geral (pais e mães, professores e professoras) têm da procrastinação em relação ao estudo das crianças e jovens de forma a poder-se encontrar formas alternativas para intervir na procrastinação (em particular) e na motivação para a aprendizagem (em geral). É ainda fundamental aprofundar o conhecimento relativo à dinâmica familiar, ao envolvimento (ou falta dele) de pais e mães no estudo diário e estudo para os testes, bem como outras variáveis que podem ter um impacto significativo na procrastinação no estudo. É imprescindível mapear os comportamentos dos professores face à procrastinação no estudo dos seus alunos.

De um ponto de vista mais geral, é fundamental consciencializar e formar professores e pais para a importância de promover a autorregulação da aprendizagem (através da formulação de objetivos, da monitorização dos progressos, da gestão do tempo), enfatizar a promoção de experiências de sucesso e a proteção dos objetivos em relação a comportamentos distratores. Bloquear o acesso a "tentações" a curto prazo pode ser, de facto, uma estratégia adequada e ser efetuada através do desenvolvimento de competências de estudo que previnam as distrações (e.g., estudar na biblioteca, manter a mesa de trabalho arrumada, não ter a TV ligada, estudar com a porta fechada, etc...). Estes aspetos poderão ajudar a aumentar o valor dos componentes motivacionais e fazer diminuir o tempo entre a exibição do comportamento e a consequente recompensa ou reforço. Simultaneamente, as expectativas de sucesso podem ser aumentadas em alunos procrastinadores através da realização de planos de trabalho 
que incluem objetivos intermédios, um ambiente de trabalho adequado e a alocação de tempo suficiente à realização da tarefa. Na sua essência, estas são técnicas especificamente indicadas para a gestão eficaz do tempo, frequentemente utilizadas em intervenções de carácter cognitivocomportamental mas que podem ter um impacto significativo na prevenção da procrastinação no estudo.

Outro aspeto a ter em conta na prática educativa prende-se com as questões volitivas. A importância da volição, em termos educacionais, tornase evidente quando nos deparamos com alunos que, apesar do seu potencial e da sua motivação inicial, recorrentemente não se aplicam no sentido de concretizarem as tarefas escolares, divergindo para os denominados “interesses laterais", perturbando o ambiente na sala de aula e ficando muito aquém das suas possibilidades de aprendizagem. Talvez em consequência deste facto, desde o início do processo de escolarização, os alunos devem ser estimulados a adotarem regras de conduta e a desenvolverem o autocontrolo (LOURENÇO; PAIVA; YOUNG; DA ROSA, 2010). À medida que os mais novos vão crescendo, tornam-se cada vez mais capazes de lidar com o trabalho escolar, mas o seu desempenho continuará a beneficiar do apuramento do controlo volitivo. Pela interiorização das regras escolares e pela assunção de responsabilidades pessoais, o aluno aprende a lidar com a crescente complexidade do estudo e do desempenho (WINNE, 1995, 1997). O processamento volitivo que leva a ações eficazes na escola ajuda a proteger e a manter as intenções dos estudantes de atingir objetivos académicos face a objetivos competidores (como socioemocionais) e outros distratores (CORNO, 1993). Por conseguinte, as estratégias volitivas permitem proteger a intenção de aprender dos distratores que possam surgir. A atividade volitiva é exteriorizada em tarefas a completar, dentro ou fora da escola (e.g., T.P.C.), bem como em tarefas que os estudantes assumem como suas. Certas condições apelam mais à volição dos estudantes do que outras; estas condições incluem a perceção de que a tarefa é muito difícil, muito fácil ou muito tediosa; ou que os objetivos são pouco valorizados, vagamente definidos ou muito complexos. A conclusão da tarefa também pode ser vista como difícil, porque o ambiente de aprendizagem está sujeito a inúmeros distratores ou porque os distratores são inevitáveis quando o trabalho é muito prolongado. 
Como nos é referido por Corno e Kanfer (1993), proteger e manter os objetivos académicos são os dois aspetos mais relevantes desta nova visão da competência volitiva. Fundamentalmente, o objetivo é identificar competências e estratégias potencialmente modificáveis em idades precoces, para que estes elementos possam ser usados para consolidar as novas aprendizagens ou aumentar o conhecimento disponível(SALOMON, 1983).

Concluindo, a investigação realizada sobre esta temática refere que a vontade dos estudantes manterem as suas intenções de aprendizagem e persistirem na mestria face a dificuldades depende da sua bagagem cognitiva e motivacional e do seu acesso a estratégias volitivas. Sugere mesmo a instrução de estratégias volitivas a crianças que necessitem de lidar, mais eficazmente, com situações difíceis na escola.

Perante este cenário, é imperioso trabalharmos a competência volitiva dos estudantes, para que estes consigam persistir nos seus objetivos académicos, não obstante as dificuldades de aprendizagem, os distratores e os objetivos concorrentes que possam surgir. Desta forma, estaremos, certamente, a contribuir para um maior sucesso académico e para uma diminuição do abandono escolar, que torna evidente a desistência pessoal de todos os objetivos académicos e, a médio e longo prazo, de muitos objetivos de realização pessoal e profissional.

Finalmente, quando aceitamos a complexidade, torna-se relativamente fácil compreender a situação concreta, de forma a criar uma organização harmoniosa e lógica das variáveis envolvidas. Quando somos capazes de compreender a importância dos métodos utilizados na aprendizagem dos nossos alunos, tendo como objetivo a mestria, o processo de mudança está iniciado e é irreversível.

\section{Referências}

ABLARD, K.; LIPSCHULTZ, D. Self-regulation in high-achieving students: relations to advanced reasoning, achievement goals, and gender. Journal of Educational Psychology, 90 (1), p. 94-101, 1998.

AMES, C. A. Motivation: what teachers need to know. Teachers College Record, 91 (3), p. 409-421, 1990. 
ANDERMAN, E. M. \& MAEHR, M. L. Motivation and schooling in the middle grades. Review of Educational Research, 64 (2), p. 287-309, 1994. BANDURA, A. Social foundations of thought and action: A social cognitive theory. Englewood Cliffs, NJ: Prentice-Hall, 1986.

BARCA, A.; PORTO, A.; SANTORUM, R. Los enfoques de aprendizajeen contextos y situaciones educativas. Una aproximación conceptual e metodológica. In: BARCA, A.; MALMIERCA, J. L.; NÚÑEZ, J. C.; PORTO, A.; SANTORUM, R. (Ed.). Procesos de aprendizaje en ambientes educativos. Madrid: Editorial Centro de Estudios Ramón Areces, 1997. p. 387-435.

BIGGS, J. B. Approaches to learning in secondary and tertiary students in Hong Kong: some comparative studies. Educational Research Journal, 6, p. 27-39, 1991.

BIGGS, J. B. What do inventories of students' learning processes really measure? Atheoretical review and clarification. British Journal of Educational Psychology, 63 (1), p. 3-19, 1993.

. Teaching for quality learning at university. 2. ed. Buckingham: Open University Press/Society for research into Higher Education, 2003.

; MOORE, P. J. The process of learning. Sydney: Prentice Hall of Australia, 1993.

BOEKAERTS, M. Personality and the Psychology of Learning. European Journal of Personality, 10, 377-404, 1996.

. Self-regulation. With a focus on the self-regulation of motivation and effort. In: RAMON, W.; LERNER R. (Series Ed.); SIGEL, I. E.; RENNINGER, K. A. (Vol. Ed.). Handbook of Child Psychology: Child psychology in practice. v. 4. 6. ed. NY: Wiley, 2005. p. 115-126.

; CORNO, L. Self-Regulation in Classroom: A Perspective on Assessment and Intervention. Applied Psychology: An International Review, 54 (2), p. 199-231, 2005.

BORUCHOVITCH, E. A motivação para aprender de estudantes em cursos de formação de professores. Educação, 31 (1), p. 30-38, 2008.

BYRNE, B. M. Structural Equation Modeling With AMOS - Basic Concepts, Applications, and Programming. NJ: Lawrence Erlbaum, 2001. 
BZUNECK, A. Uma abordagem sócio-cognitivista à motivação do aluno: A teoria de metas de realização. Psico-USF, 4 (2), p. 51-66, 1999.

CORNO, L. The best-laid plans. Modern conceptions of volition and educational research. Educational Research, 22, p. 14-22, 1993.

. Work habits and work styles: Volition in education. Teachers College Record, 106, p. 1669-1694, 2004.

; KANFER, R. The role of volition in learning and performance. In: DARLING-HAMMOND, L. Review of Research in Education. v. 19. Washington, DC: American Educational Research Association, 1993. p. 301-341.

DE VOLDER, M. L.; LENS, W. Academic achievement and future time perspective as a cognitive-motivational concept. Journal of Personality and Social Psychology, 42 (3), p. 566-571, 1982.

DECI, E. L. The "What" and "Why" of Goal Pursuits: Human Needs and the Self-Determination of Behavior. Psychological Inquiry, 11(4), p. 227268, 2000.

. RYAN, R. M. Intrinsic motivation and self-determination in human behavior. NY: Plenum Press, 1985.

DEWITTE, S.; LENS, W. Procrastinators lack a broad action perspective. European Journal of Personality, 14, p. 121-140, 2000.

ELLIOTT, E.; DWECK, C. S. Goals: An approach to motivation and achievement. Journal of Personality and Social Psychology, 54 (1), p. 5-12, 1988.

ENTWISTLE, N. J. Motivational factors in students' approaches to learning. In: SCHMECK, R. R. (Ed.). Learning Strategies and Learning Styles. NY: Plenum Press, 1988. p. 1-51.

. Frameworks for Understanding as Experienced in Essay Writing and in Preparing for Examinations. Educational Psychologist, 30 (1), p. 47-54, 1995.

FEARN-WANNAN, H.(1980). Students' of lecturers as determinants of academic performance in first-year chemistry. In: BILLING, D. (Ed.). Course design and student learning. Guildonf: SRHE, 1980. p. 76-89. 
FERRARI, J.; HARRIOTT, J.; EVANS, L.; LECIK-MICHNA, D.; WENGER, J. Exploring the time preferences by procrastinators: Night or day, which is the one? European Journal of Personality, 11 (3), p. 187-196, 1997.

; JOHNSON, J.; MCCOWN, W. Procrastination and task avoidance: Theory, research and practice. NY: Plenum Press, 1995.

; O'CALlAGHAN, J.; NEWBEGIN, I. Prevalence of procrastination in the United States, United Kingdom, and Australia: arousal and avoidance delays among adults. North American Journal of Psychology, 7 (1), p. 1-6, 2005.

FIGUEIRA,A.P. C. Em torno do rendimento escolar. 1994. Tese (Mestrado) - Faculdade de Psicologia e Ciências da Educação da Universidade de Coimbra, Coimbra, 1994.

GAINE, C.; GEORGE, R. Gender, “race”, and class in schooling. London: Falmer Press, 1999.

GIBBS, G. Improving the Quality of Student Learning. Bristol: Technical and Educational Services, 1992.

HARRIS, N.; SUTTON, R. Task procrastination in organizations: A framework for research. Human Relations, 36 (11), p. 987-995, 1983.

KARABENICK, S. A. Help seeking as a strategic resource. In: KARABENICK, S. A. (Ed.). Strategic help seeking: Implications for learning and teaching. Mahwah, NJ: Erlbaum, 1998. p. 1-11.

KUHL, J. Volitional mediators of cognitive behavior consistency: Selfregulatory processes and action versus state orientation. In:

BECKMAN, J. (Ed.). Action control. NY: Springer, 1985. p. 101-128.

LENS, W. La signification motivationnelle de la perspective future. Revue Québécoise de Psychologie, 14 (1), p. 69-83, 1993.

LOPES DA SILVA, A. ; SÁ, I. Auto-Regulação e Aprendizagem. Investigar em Educação. Revista da Sociedade Portuguesa de Ciências da Educação, 2, p. 71-90, 2003.

LOURENÇO, A. A. Multiculturalidade, etnia e personalidade. Revista de Psiquiatria e Psicologia, 25, 1-2-3-4, p. 29-50, 2004. 
- Processos Auto-Regulatórios em Alunos do $3^{\circ}$ Ciclo do Ensino Básico: Contributos da Auto-Eficácia a da Instrumentalidade. 2008. Dissertação (Doutorado em Educação). Instituto de Educação e Psicologia da Universidade do Minho, Braga, 2008. Não publicada.

; PAIVA, M. O. A. Conflitos na escola: a importância da amabilidade na negociação. Educação e Filosofia, 23 (46), p. 145-168, 2009.

; DA ROSA, V. M. P.; PAIVA, M. O. A. Ambiente psicossociológico da sala de aula e rendimento escolar: um estudo de caso. Revista da Faculdade de Ciências Humanas e Sociais, 7, p. 276-289, 2010. ; PAIVA, M. O. A. A motivação escolar e o processo de aprendizagem. Ciências \& Cognição, 15 (2), p. 132-141, $2010 \mathrm{a}$.

; PAIVA, M. O. A. A percepção do clima de escola pelos alunos da ESAH. In: SEMINÁRIO INTERNACIONAL CONTRIBUTOS DA PSICOLOGIA EM CONTEXTOS EDUCATIVOS, 1., 2010, Braga. Actas... Braga: Edição Universitária, 2010b. (Apresentação de trabalho).

; ROSÁRIO, P.; SALGADO, A.; GUIMARÃES, C.; TRIGO, L.; BALDAQUE, M.; COSTA, M.; PAIVA, M. O. A; SANTOS, L.; MOURÃO, R.; MAGAlHÃES, C.; VALLE, A.; NÚÑEZ, J. C. \& GONZÁLEZ-PIENDA, J. Processos auto-regulatórios em alunos do $3^{\circ}$ Ciclo do Ensino Básico: Auto-eficácia e instrumentalidade. In: CONGRESSO INTERNACIONAL DE AVALIAÇÃO PSICOLÓGICA: FORMAS E CONTEXTOS, 13., 2008, Braga: Edição Universitária. (Apresentação de trabalho).

; PAIVA, M. O. A.; YOUNG, N.; DA ROSA, V. P. Effects of personality on interpersonal negotiation strategies and self-presentation in a school setting. Psique, 6 (1), p. 7-27, 2010.

LOWE, B.; WARD, S.; WINZAR, H. (2007). Essentials of SPSS for Windows Versions 14 and 15. Australia: Cengage Learning, 2007.

MAIA, J. A. R.; GRAÇA, A. Validade de construto e invariância configuracional de instrumentos psicológicos. Uma abordagem psicológica a partir da teoria psicométrica e do LISREL. In: CONGRESSO DE EDUCAÇÃO FÍSICA E CIÊNCIAS DO DESPORTO DOS PAÍSES DE LÍNGUA PORTUGUESA, 5., 1995, Coimbra. Anais... Coimbra. (Apresentação de comunicação). 
MARTON, F. What does it take to learn? In: ENTWISTLE, N. J. (Ed.). Strategies for researchand development in higher education. Amsterdam: Swets and Zeitlinger, 1975. p. 32-43.

. Describing and Improving Learning. In: SCHMECK, R. (Ed.). Learning strategies and learning styles. NY: Plenum Press, 1988. p. 53-82.

MARTON, F.; BOOTH, S. Learning and awareness. NJ: Lawrence Erlbaum, 1997.

; CARLSSON, M. A.; HALÁSZ, L. Differences in understanding and the use of reflective variation in reading. British Journal of Educational Psychology, 62, p. 1-16, 1992.

; HOUNSELL, D.; ENTWISTLE, N. (Ed.). The Experience of Learning. Edinburgh: Scottish Academic Press Limited, 1997.

; SÄLJÖ, R. On qualitative differences in learning: I Outcome and Process. British Journal of Educational Psychology, 46, p. 4-11, 1976a.

; SÄLJÖ, R. On qualitative differences in learning: II. Outcome as a function of the learner's conception of the task. British Journal of Educational Psychology, 46, p. 115-127, 1976 b.

; SÄLJÖ, R. Approaches to learning. In: MARTON, F.; HOUNSELL, D.; ENTWISTLE, N. (Ed.). The Experience of Learning. Edinburgh: Scottish Academic Press Limited, 1997. p. 39-58.

; WATKINS, D.; TANG, C. Discontinuities and continuities in the experience of learning: An interview study of high-school students in Hong-Kong. Learning and Instruction, 7 (1), p. 21-48, 1997.

; WEN, Q.; NAGLE, A. Views on learning in different cultures. Comparing patterns in China and Uruguay. Anales de Psicologia, 12 (2), p. 123-132, 1996.

MONTERO, C. R.; TORRES, M. G. Capacidad de autorregulación del proceso de aprendizaje. In: GONZÁLEZ-PIENDA, J. A.; PÉREZ Núnez (Coord.). Dificultades del aprendizaje escolar. Madrid: Psicología Pirámide, 1998. p. 239-259. 
MONTGOMERY, D. Enhancing student learning in higher education through the development and use of cognitive process strategies. In: GIBBS, G. (Ed.). Improving student learning-theory and practice. Oxford: The Oxford Centre of Staff Development, 1994. p. 36-49.

NEWMAN, R. S. Academic help-seeking: A strategy of self-regulated learning. In: SCHUNK, D. H.; ZIMMERMAN, B. J. (Ed.). Self-regulation of learning and performance: Issues and educational applications. Hillsdale: Erlbaum, 1994. p. 283-301.

NICHOLLS, J.Achievement motivation: Conceptions of ability, subjective experience, task choice, and performance. Psychological Review, 91, p. 328-346, 1984.

NÚÑEZ, J. C.; SOLANO, P.; GONZÁLEZ-PIENDA, J. A.; ROSÁRIO, P. El aprendizaje autoregulado como medio y meta de la educación. Papeles del Psicólogo, 27 (3), p. 141-148, 2006.

NUTTIN, J. C. Théorie de la motivation humaine. Paris: Presses Universitaires de France, 1985.

; LENS, W. Future time perspective and motivation: Theory and research method. Louvain: Presses Universitaires de Louvain, 1985.

PAIVA, M. O. A. Abordagens à aprendizagem e abordagens ao ensino: Uma aproximação à dinâmica do aprender no Secundário. 2008. Dissertação (Doutorado em Educação). Instituto de Educação e Psicologia da Universidade do Minho, Braga, 2008. Não publicada.

; LOURENÇO, A. A. Inventário de Percepções de Ambiente de Ensino (IPAE): Validação numa perspectiva exploratória. Psicologia, Educação e Cultura, 15 (1), p. 23-35, 2011 a.

; LOURENÇO, A. A. Ambiente da sala de aula: um estudo de caso. Educação e Filosofia, 25 (49), p. 17-42, 2011 b.

; LOURENÇO, A. A. Rendimento Académico: Influência do Autoconceito e do Ambiente de Sala de Aula. Psicologia: Teoria e Pesquisa, 27 (4), p. 393-402, $2011 \mathrm{c}$.

PEREZ, J. N.; GONZALEZ-PIENDA, J. A.; RODRIGUEZ, M. Aprender en la escuela. In: GONZÁLEZ-PIENDA, J. A.; PÉREZ Núnez (Coord.). Dificultades del aprendizaje escolar. Madrid: Psicología Pirámide, 1998. p. 21-43. 
PINTRICH, P. R. The role of goal orientation in self-regulated learning. In: BOEKAERTS, M.; PINTRICH, P.; ZEIDNER, M. (Ed.). Handbook of self-regulation. San Diego: Academic Press, 2000. p. 451-502.

- A motivational science perspective on the role of student motivation in learning and teaching contexts. Journal of Educational Psychology, 95, p. 667-686, 2003.

; ZUSCHO, A. The development of academic self-regulation: the role of cognitive and motivational factores. In: WIGFIELD, A.; ECCLES, J. (Ed.). Development of achievement motivation. NY: Academic Press, 2002. p. 250-271.

PROSSER, M.; TRIGWELL, K. Understanding Learning and Teaching: The Experience in Higher Education. Buckingham: Open University Press, 2000.

RAMSDEN, P. Learning to Teach in Higher Education. London: Routledge, 1992.

REEVE, J.; DECI, E. L.; RYAN, R. M. Self-determination theory: a dialectical framework for understanding sociocultural influences on student motivation. In: MC INERNEY, Dennis; VAN ETTEN, Shawn (Ed.). Big theories revisited. Greenwich: Information Age Publishing, 2004. p. 31-60. RICHARDSON, J. T. E. Meaning orientation and reproducing orientation: A typology of approaches to studying in higher education? Educational Psychology, 17 (3), p. 301-311, 1997.

ROSÁRIO, P. Variáveis Cognitivo-motivacionais na Aprendizagem: As "Abordagens ao Estudo" em alunos do Ensino Secundário. 1999. Tese (Doutorado em Psicologia) - Universidade do Minho, Braga, 1999.

; COSTA, M. A procrastinação, auto-regulação e género. 2007. Dissertação (Mestrado)-Universidade do Minho, Braga, 2007.

ROSÁRIO, P.; GRÁCIO, L.; NÚNEZ, J. C.; GONZÁLEZ-PIENDA, J. Voix d'élèves sur l'apprentissage à l'entrée et à la sortie de l'université: un regard phénoménographique. Revue des Sciences de l'éducation, 33 (1), p. 237-262, 2007.

; LOURENÇO, A. A.; PAIVA, M. O.; NÚÑEZ, J. C.; GONZÁLEZ-PIENDA, J.; VALLE, A. Inventário de processos de autoregulação da aprendizagem (IPAA). In: MACHADO, C.; GONÇALVES, 
M. M.; ALMEIDA, L. S.; SIMÕES, M. R. (Coord.). Instrumentos e Contextos da Avaliação Psicológica. v. I. Coimbra: Almedina, 2011. p. 159-174.

; FERREIRA, I.; CUNHA, A. Inventário de Processos de Estudo (IPE). In: GONÇALVES, M.; SIMÕES,M.; ALMEIDA, L.; MACHADO, C. (Coord.). Avaliação psicológica: instrumentos validados para a população portuguesa. v. 1. Coimbra: Quarteto Editora, 2003.

; FERREIRA, I.; GUIMARÃES, C. Abordagens ao estudo em alunos de alto rendimento. Sobredotação, 2 (2), p. 121-137, 2001.

; MOURÃO, R.; SALGADO, A.; RODRIGUES, A.; SILVA, C.; MARQUES, C.; AMORIM, L.; MACHADO, S.; NÚÑEZ, J.; GONZÁLEZ-PIENDA, J.; HERNÁNDEZ-PINA, F. Trabalhar e estudar sob a lente dos processos e estratégias de auto-regulação da aprendizagem. Psicologia, Educação e Cultura, 10 (1), p. 77-88, 2006.

; NÚÑEZ, J. C.; GONZÁLEZ-PIENDA, J. Sarilhos do Amarelo. Porto: Porto Editora, 2007.

. NÚÑEZ, J. C.; GONZÁLEZ-PIENDA, J. A.; ALMEIDA, L.; SOARES, S.; RÚBIO, M. El aprendizaje escolar examinado desde la perspectiva del "Modelo 3P" de J. Biggs. Psicothema, 17 (1), p. 20-30, 2005.

; SOARES, S.; NÚÑEZ, J. C.; GONZÁLEZ-PIENDA, J.; RÚBIO, M. Auto-regulação da aprendizagem em contexto escolar: questões e discussões. In: ENCONTRO DO GRUPO DE TRABALHO PEDAGOGIA PARA AAUTONOMIA(GT-PA), 2., 2003, Braga, Portugal. Actas... Braga, Portugal: Universidade do Minho, 2003.

RYAN, R. M.; DECI, E. L. Self-determination theory and facilitation of intrinsic motivation, social development and well-being. American Psychologist, 55 (1), p. 68-78, 2000.

; PINTRICH, P. R. Should I ask for help? The role of motivation and attitudes in adolescents' help seeking in math class. Journal of Educational Psychology, 89, p. 329-341, 1997.

SÄLJÖ, R. Learning and Understanding: A Study of Differences in Constructing Meaning from a Text. Göteborg: Acta Universitatis Gothoburgensis, 1982. (Göteborg Studies in Educational Sciences, n. 41) 
SALOMON, G. The differential investment of mental effort in learning from different sources. Educational Psychologist, 18(1), p. 42-50, 1983.

SENÉCAL, C.; KOESTNER, R.; VALLERAND, R. Self-regulation: an academic procrastination. The Journal of Social Psychology, 135, 5, p. 607-619, 1995.

SCHER, S.; OSTERMAN, N. Procrastination, conscientiousness, anxiety, and goals: exploring the measurement and correlates of procrastination among school-aged children. Psychology in the Schools, 39 (4), p. 385398, 2002.

SCHOUWENBURG, H. Trait procrastination in academic settings: An overview of students who engage in task delays. In: SCHOUWENBURG, H.; LAY, C.; PYLCHYL, T.; FERRARI, J. (Ed.). Counselling the procrastinator in academic settings. Washington: American Psychological Association, 2004. p. 3-18.

SCHUNK, D. H. The self-efficacy perspective on achievement behaviour. Educational Psychologist, 19, p. 199-218, 1984.

. Self-efficacy and academic motivation. Educational Psychologist, 26, p. 207-231, 1991.

. Self-regulation of self-efficacy and attributions in academic settings. In: SCHUNK, D. H.; ZIMMERMAN, B. J. (Ed.). Self-regulation of learning and performance: Issues and educational applications. Hillsdale: Erlbaum, 1994. p. 75-99.

. Goal and self-evaluative influences during children's cognitive skill learning. American Educational Research Journal, 33, p. 359-382, 1996a.

.Teaching elementary students to self-regulated practice of Mathematical skills with modeling. In: SCHUNK, D. H.; ZIMMERMAN, B. J. (Ed.). Self-regulated learning: From teaching to self-reflective practice. Hillsdale, NJ: Lawrence Erlbaum Associates, 1998. p. 137-159.

. Social Cognitive Theory and Self-Regulated Learning. In: ZIMMERMAN, B. J.; SCHUNK, D. H. (Ed.) Self-regulated learning and academic achievement: Theoretical Perspectives. 2. ed. New Jersey: Lawrence Erlbaum Associates, 2001. p. 125-151. 
. Commentary on self-regulation in school contexts. Learning and Instruction, 15, p. 173-177, 2005.

TIMOTHY, J. C.; ZIMMERMAN, B. J. Self-Regulation Empowerment Program to Enhance Self-Regulated and Self-Motivated Cycles of Student Learning. Psychology in the Schools, 41 (5), p. 537-550, 2004.

VANSTEENKISTE, M.; SIMONS, J.; LENS, W.; SHELDON, K. M.; DECI, E. L. Motivating learning, performance, and persistence: The synergistic effects of intrinsic goal contents and autonomy-supportive contents. Journal of Personality and Psychology, 87, p. 246-260, 2004.

WINNE, P. H. Inherent details in self-regulated learning. Educational Psychology, 71, p. 3-25, 1995.

. Experimenting to bootstrap self-regulated learning. Journal of Educational Psychology, 89 (3), p. 397-410, 1997.

YOWELL, C. M.; SMYLIE, M. A. Self-regulation in democratic communities. Elementary School Journal, 99, p. 469-490, 1999.

ZIESAT, H.; ROSENTHAL, T.; WHITE, G. Behavioural self-control in treating procrastination of studying. Psychological Reports, 42, p. 59-69, 1978.

ZIMMERMAN, B. J. Model of self-regulated learning and academic achievement. In: ; SCHUNK, D. H. (Ed.). Self-regulated learning and academic achievement: Theory, research and practice. NY: Springer-Verlag, 1989a. p. 1-25.

- A Social Cognitive View of Self-Regulated Academic Learning. Journal of Educational Psychology, 81 (3), p. 329-339, 1989b.

. Dimensions of academic self-regulation: A conceptual frame-work for education. In: SCHUNK, D. H.; ZIMMERMAN, B. J. (Ed.). Self-regulation of learning and performance: Issues and educational applications. Hillsdale, NJ: Erlbaum, 1994. p. 3-21.

. Developing self-fulfilling cycles of academic regulation: An analysis of exemplary instructional models. In: SCHUNK, D. H.; ZIMMERMAN, B. J. (Ed.). Self-regulated learning: From teaching to self-reflective Practice. NY: The Guilford Press, 1998. p. 1-19.

. Commentary: toward a cyclicaly interactive view of self- 
regulated learning. International Journal of Educational Research, 31, p. 545-551, 1999.

. Attaining self-regulation: A social cognitive perspective. In: BOEKAERTS, M.; PINTRICH, P.; ZEIDNER, M. (Ed.). Hanbook of selfregulation. NY: Academic Press, 2000. p. 13-39.

. Becoming a Self-Regulated Learner: An Overview. Theory Into Practice, 41 (2), p. 64-70, 2002.

; BONNER, S.; KOVACH, R. Developing self-regulated learners: Beyond achievement to self-efficacy. Washington, DC: American Psychological Association, 1996.

; MARTINEZ-PONS, M. Construct validation of a strategy model of student self-regulated learning. Journal of Educational Psychology, 80, p. 284-290, 1988.

; MARTINEZ-PONS, M. Student differences in self-regulated learning: Relating grade, sex, and giftedness to self-efficacy and strategy use. Journal of Educational Psychology, 82 (1), p. 51-59, 1990.

; MARTINEZ-PONS, M. Perceptions of efficacy and strategy use in the self-regulation of learning. In: SCHUNK, D. H.; MEESE, J. (Ed.). Student perceptions in classroom: causes and consequences. Hilldale, NJ: Erlbaum, 1992.

; PAULSEN, A. S. Self-monitoring during collegiate studing: An invaluable tool for academic self-regulation. In: PINTRICH, P. (Ed.). New directions in college teaching and learning: Understanding selfregulated learning. San Francisco, CA: Jossey-Bass, 1995. p. 13-27.

; RISEMBERG, R. Research for the future. Becoming a selfregulated writer: A social cognitive perspective. Contemporary Educational Psychology, 22, p. 73-101, 1997.

; SCHUNK, D. H. Self-regulated learning: From teaching to self-reflective practice. NY: Guilford, 1998.

Data de registro: 07/02/2013

Data de aceite: 20/11/2013 